OPEN ACCESS

Edited by:

Teresa Zotta,

Italian National Research Council, Italy

Reviewed by:

Albert Bordons,

Rovira i Virgili University, Spain

Giuseppe Spano,

University of Foggia, Italy

Vittorio Capozzi,

University of Foggia, Italy

*Correspondence:

Cosette Grandvalet

cosette.grandvalet@u-bourgogne.fr

${ }^{\dagger}$ These authors have contributed equally to this work

Specialty section:

This article was submitted to

Food Microbiology,

a section of the journal

Frontiers in Microbiology

Received: 15 October 2018

Accepted: 04 December 2018

Published: 18 December 2018

Citation:

Darsonval M, Julliat F, Msadek T, Alexandre H and Grandvalet C (2018)

CtsR, the Master Regulator

of Stress-Response in Oenococcus

oeni, Is a Heat Sensor Interacting

With ClpL1. Front. Microbiol. 9:3135.

doi: 10.3389/fmicb.2018.03135

\section{CtsR, the Master Regulator of Stress-Response in Oenococcus oeni, Is a Heat Sensor Interacting With ClpL1}

\author{
Maud Darsonval'1+, Frédérique Julliat ${ }^{1 \dagger}$, Tarek Msadek ${ }^{2,3}$, Hervé Alexandre ${ }^{1,4}$ and \\ Cosette Grandvalet ${ }^{1,5 *}$
}

' UMR A. 02.102 Procédés Alimentaires et Microbiologique, AgroSup Dijon, Université Bourgogne Franche-Comté, Dijon, France, ${ }^{2}$ Unité de Biologie des Bactéries Pathogènes à Gram Positif, Institut Pasteur, Paris, France, ${ }^{3}$ CNRS ERL 6002, Paris, France, ${ }^{4}$ Institut Universitaire de la Vigne et du Vin - Jules Guyot, Dijon, France, ${ }^{5}$ Institut National Supérieur des Sciences Agronomiques, de L'Alimentation et de L'Environnement, AgroSup Dijon, Dijon, France

Oenococcus oeni is a lactic acid bacterium responsible for malolactic fermentation of wine. While many stress response mechanisms implemented by $\mathrm{O}$. oeni during wine adaptation have been described, little is known about their regulation. CtsR is the only regulator of stress response genes identified to date in $\mathrm{O}$. oeni. Extensively characterized in Bacillus subtilis, the CtsR repressor is active as a dimer at $37^{\circ} \mathrm{C}$ and degraded at higher temperatures by a proteolytic mechanism involving two adapter proteins, McsA and McsB, together with the ClpCP complex. The $O$. oeni genome does not encode orthologs of these adapter proteins and the regulation of CtsR activity remains unknown. In this study, we investigate CtsR function in $O$. oeni by using antisense RNA silencing in vivo to modulate $c t s R$ gene expression. Inhibition of $c t s R$ gene expression by asRNA leads to a significant loss in cultivability after heat shock (58\%) and acid shock (59\%) highlighting the key role of CtsR in the O. oeni stress response. Regulation of CtsR activity was studied using a heterologous expression system to demonstrate that O. oeni CtsR controls expression and stress induction of the O. oeni hsp18 gene when produced in a ctsR-deficient $B$. subtilis strain. Under heat stress conditions, O. oeni CtsR acts as a temperature sensor and is inactivated at growth temperatures above $33^{\circ} \mathrm{C}$. Finally, using an E. coli bacterial two-hybrid system, we showed that CtsR and ClpL1 interact, suggesting a key role for ClpL1 in controlling CtsR activity in O. oeni.

Keywords: Oenococcus oeni, stress response, CtsR, RNA silencing, heterologous expression system, two-hybrid system

\section{INTRODUCTION}

Oenococcus oeni is an acidophilic wine-associated lactic acid bacterium (LAB), mainly responsible for malolactic fermentation (MLF) of wine, usually following yeast-driven alcoholic fermentation (Lonvaud-Funel, 1999). Wine and the winemaking process form a harsh and challenging environment combining stresses such as low $\mathrm{pH}(3-3.5)$, low temperatures $\left(14-18^{\circ} \mathrm{C}\right)$, the presence of ethanol, nutrient starvation and competing organisms (yeasts) generating abiotic growth 
inhibitors (ethanol, sulfites, decanoic, and dodecanoic acids). Like most microorganisms facing stress conditions, O. oeni must adapt to survive and deciphering the molecular mechanisms involved in responding to stress is an important step to improve O. oeni MLF performance and design future malolactic starter strains. Because of its acidophilic profile and its unique genome organization, O. oeni is an intriguing and challenging model to investigate stress response mechanisms in LAB (Bartowsky, 2017; Grandvalet, 2017). Over the past decades, several genetic responses adopted by $O$. oeni during wine adaptation have been described, including genes involved in general stress response, membrane composition and fluidity, $\mathrm{pH}$ homeostasis, oxidative stress response, presence of sulfites and DNA damage (Salema et al., 1996; Guzzo et al., 1997, 1998; Jobin et al., 1997, 1999; Tourdot-Maréchal et al., 2000; Da Silveira et al., 2003; Beltramo et al., 2004; Chu-Ky et al., 2005; Coucheney et al., 2005b; Grandvalet et al., 2005, 2008; Da Silveira and Abee, 2009; Maitre et al., 2014; Darsonval et al., 2016; Margalef-Català et al., 2016).

Oenococcus oeni stress response mechanisms involve the synthesis of Heat Shock Proteins (HSPs), a universal stress response with several regulatory pathways described in Firmicutes. Indeed, $h s p$ genes can be induced by the alternative sigma factor $\sigma^{B}$ or repressed by transcriptional repressors such as CtsR or HrcA (Benson and Haldenwang, 1993; Schulz and Schumann, 1996; Derré et al., 1999; Schumann, 2003). In Streptococci, HrcA and CtsR control two partially overlapping regulons that include most hsp genes (Chastanet et al., 2001; Chastanet and Msadek, 2003; Grandvalet et al., 2005; Spano and Massa, 2006; Frees et al., 2007). In contrast, in Bacilli, the two regulons are entirely distinct while in Staphylococci the HrcA regulon is completely embedded within the CtsR regulon (Chastanet et al., 2003). Both transcriptional repressors control expression of their regulon by specifically binding to their operator sequences in the promoter region, preventing RNA polymerase recruitment. HrcA specifically recognizes the CIRCE ("Controlling inverted repeat of chaperone expression") palindromic sequence while CtsR binds a tandemly repeated hepta-nucleotidic operator sequence (Zuber and Schumann, 1994; Derré et al., 1999). CtsR is the only regulator of stress response gene expression identified and studied in $O$. oeni so far (Grandvalet et al., 2005). The sequence analysis of the scaffold O. oeni ATCC BAA-1163 genome ${ }^{1}$ allowed the identification of the $c t s R$ gene sequence and CtsR operator sequences, but no $h r c A$ gene, CIRCE sequences or other genes encoding known stress response regulators have been found. Likewise in O. oeni PSU-1 (NC_008528), the only complete sequenced strain, no gene encoding known regulators of stress response have been identified, except $c s t R$. In contrast, six two-component systems (TCS), some of which may be involved in stress response, have been identified in the O. oeni genome (Zúñiga et al., 2011). In Firmicutes, most molecular chaperone genes (dnaK, groEL) and clp genes, encoding either ClpATPases and ClpP protease, have CtsR operator sites in their promoter region. To date, O. oeni is the only Firmicutes where expression of dnaK and groEL is controlled exclusively by CtsR and not by

\footnotetext{
${ }^{1}$ http://www.ncbi.nlm.nih.gov/nuccore/AAUV00000000.1
}

HrcA (Grandvalet et al., 2005). In Bacillus subtilis, CtsR is active as a dimer under optimal growth conditions and represses transcription of its regulon by binding its operator sequence (Derré et al., 1999, 2000). Under stress conditions, the CtsR dimer is phosphorylated by McsA and McsB and then recognized and degraded by the ClpCP proteolytic complex (Derré et al., 2000; Kirstein et al., 2005, 2007; Elsholz et al., 2010, 2011). LAB are $m c s A B$-deficient Firmicutes and alternative mechanisms for regulating the CtsR activity have been described. In Lactococcus lactis, ClpE is required to restore repression by CtsR after heat shock. Indeed, replacement of $c l p E$ by $m c s A$ was shown to restore $h s p$ gene repression suggesting that $\mathrm{ClpE}$ in L. lactis has the same function as McsA in B. subtilis by interacting with CtsR through its zinc finger motif (Varmanen et al., 2003). More recently, Tao and Biswas (2013) showed that the ClpCP complex is not required for specific degradation of CtsR in Streptococcus mutans but that $\mathrm{ClpL}$ displays a chaperone protective role helping CtsR to bind its operator sequence (Tao et al., 2012; Tao and Biswas, 2013). In addition, in L. lactis, Geobacillus stearothermophilus, and B. subtilis, CtsR has been shown to act directly as a heat sensor with distinct species-specific thermal derepression temperature thresholds (Elsholz et al., 2010). The $O$. oeni genome does not contain $c l p E, m c s A$, and $m c s B$ genes, however two $c l p L$ genes are present: $c l p L 1$, in an operon with clpP, and clpL2 (Beltramo et al., 2006; Assad-García et al., 2008). This strongly suggests a likely involvement of ClpL1 and/or ClpL2 in the regulation of CtsR activity in O. oeni. O. oeni is not readily genetically tractable, few genetic tools are available and none for directed mutagenesis or gene deletion. Because of these technical barriers, the in vivo function of CtsR and the regulatory mechanisms controlling its activity in O. oeni remain unknown.

In this study, we first investigated the in vivo role of CtsR in $O$. oeni using antisense RNA silencing, a technique we recently used to show the first modulation of gene expression in O. oeni and confirm the molecular chaperone role of the small Hsp Lo18 (Darsonval et al., 2016). Using this approach, we inhibited $c t s R$ gene expression by producing a full-length antisense RNA (asRNA) of the ctsR mRNA. We then used B. subtilis 168 as a tool to explore regulation of CtsR activity. We combined a xyloseinducible heterologous expression system and a $\beta$-galactosidase reporter system based on a transcriptional fusion with the O. oeni hsp18 promoter to measure repression by O. oeni CtsR at different temperatures. Finally, we tested protein-protein interactions between CtsR and target Clp ATPases using an E. coli two-hybrid system (Karimova et al., 1998) to identify direct partners of CtsR.

\section{MATERIALS AND METHODS}

\section{Bacterial Strains and Growth Conditions}

Bacterial strains used in this study are listed in Table $\mathbf{1 .}$

Oenococcus oeni ATCC BAA-1163 is an acidophilic strain isolated in Aquitaine (France) from red wine (Lonvaud-Funel, 1999). O. oeni was grown at $28^{\circ} \mathrm{C}$ in FT80m medium $(\mathrm{pH}$ 5.3) (Cavin et al., 1989) supplemented with $20 \mu \mathrm{g} \cdot \mathrm{ml}^{-1}$ of vancomycin, $20 \mu \mathrm{g} \cdot \mathrm{ml}^{-1}$ of lincomycin and $20 \mu \mathrm{g} \cdot \mathrm{ml}^{-1}$ of erythromycin when required. For stress survival tests, cells 
TABLE 1 | Bacterial strains or plasmids used in this study.

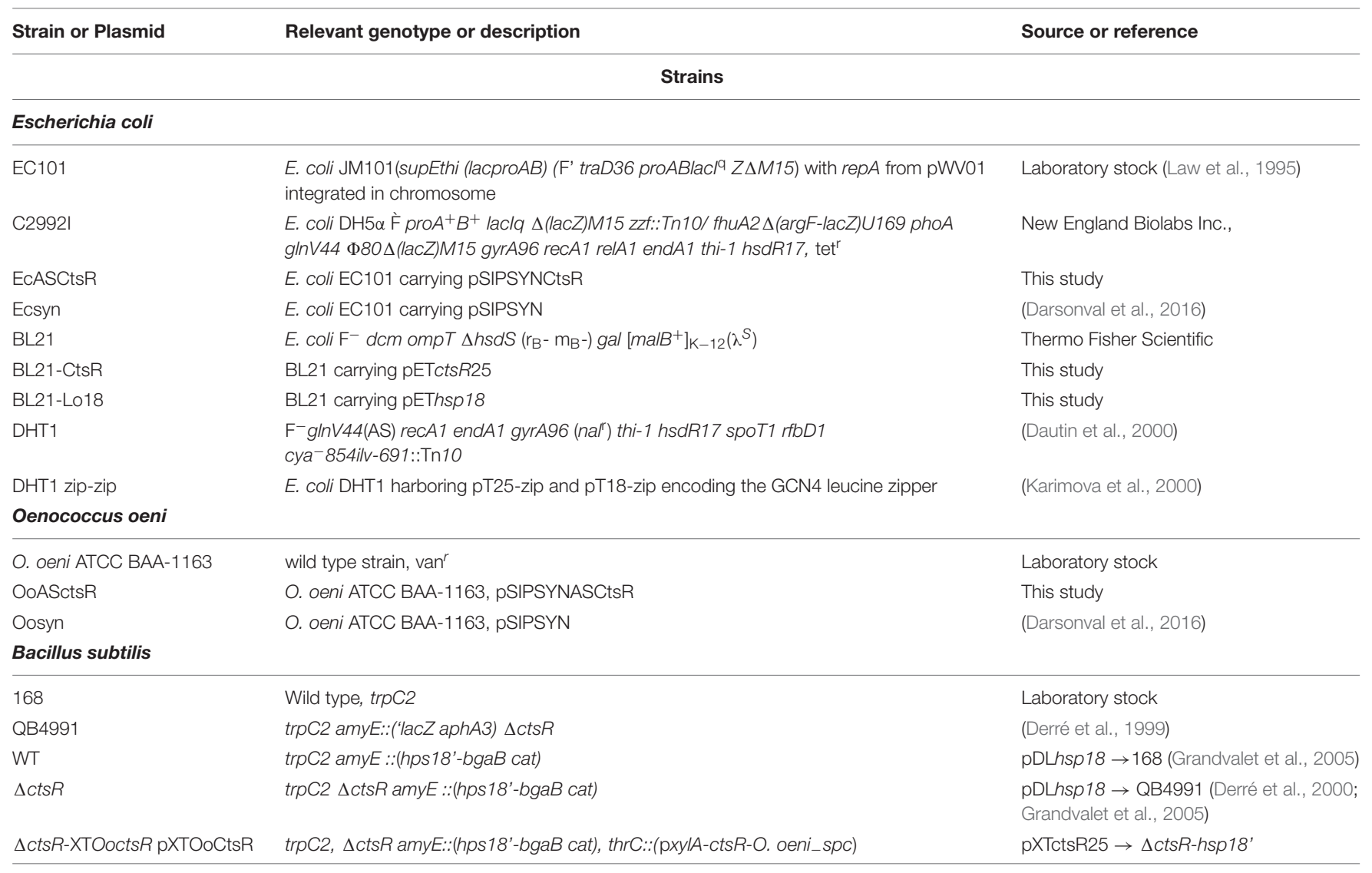

\section{Plasmids}

\begin{tabular}{|c|c|c|}
\hline pSIPSYN & $\begin{array}{l}\text { Replicative and low-copy number plasmid allowing gene expression in } \mathrm{O} \text {. oeni under the } \\
\text { control of } P_{S Y N} \text { promoter, ery }{ }^{R}\end{array}$ & (Darsonval et al., 2016) \\
\hline pSIPSYNASCtsR & $\begin{array}{l}\text { pSIPSYN derivative encoding the cts } R \text { ORF in antisense orientation under the control of } \\
\text { PSYN promoter }\end{array}$ & This study \\
\hline $\mathrm{pET} 28 \mathrm{a}(+)$ & $\begin{array}{l}\text { Vector for expression of } \mathrm{N} \text {-terminal His-tagged proteins in BL21 under the control of } \\
\text { pT7 promoter, kan }{ }^{R}\end{array}$ & Novagen \\
\hline pETctsR & pET28a(+) derivative carrying the $O$. oeni cts $R$ coding sequence, kan $^{R}$ & This study \\
\hline pEThsp18 & pET28a(+) derivative carrying the $O$. oeni hsp18 coding sequence. & This sudy \\
\hline pXT & $\begin{array}{l}\text { pDG1728 derivative allowing transcriptional fusion with } P_{x y \mid A} \text { xylose inducible promoter } \\
\text { and integration into the } B \text {. subtilis thrC locus, } \text { spec }^{R}, a^{R} p^{R}\end{array}$ & (Derré et al., 2000) \\
\hline pXTctsR25 & $\begin{array}{l}\text { pXT derivative carrying the } O \text {. oeni cts } R \text { coding sequence under the control of } P_{x y \mid A} \\
\text { xylose inducible promoter }\end{array}$ & This study \\
\hline $\mathrm{pDL}$ & $\begin{array}{l}\text { Integrative plasmid for constructing transcriptional fusions with the } \\
\text { G. stearothermophilus bgaB gene and integration into the } B \text {. subtilis amyE locus, } \mathrm{cm}^{R}\end{array}$ & (Yuan and Wong, 1995) \\
\hline pDLhsp18 & $\mathrm{pDL}$ derivative with transcriptional fusion $h s p 18^{\prime}-\mathrm{bgaB}$ & (Grandvalet et al., 2005) \\
\hline pKT25 & $\begin{array}{l}\text { BACTH vector designed to express in DHT1 a given polypeptide fused in frame at its } \\
\mathrm{N} \text {-terminal end with T25 fragment, } \mathrm{kan}^{\mathrm{R}}\end{array}$ & (Karimova et al., 2000) \\
\hline pKNT25 & $\begin{array}{l}\text { BACTH vector designed to express in DHT1 a given polypeptide fused in frame at its } \\
\text { C-terminal end with T25 fragment, } \text { ann }^{R}\end{array}$ & (Karimova et al., 2000, 2 \\
\hline pUT18C & $\begin{array}{l}\text { BACTH vector designed to express in DHT1 a given polypeptide fused in frame at its } \\
N \text {-terminal end with } T 18 \text { fragment, } a m p^{R}\end{array}$ & (Karimova et al., 2000) \\
\hline pUT18 & $\begin{array}{l}\text { BACTH vector designed to express in DHT1 a given polypeptide fused in frame at its } \\
\text { C-terminal end with } T 18 \text { fragment, } a m p^{R}\end{array}$ & (Karimova et al., 2000) \\
\hline pKT25-ctsR & Full-length ctsRORF cloned into pKT25 & This study \\
\hline pKT25-clpC & Full-length clpCORF cloned into pKT25 & This study \\
\hline pKT25-c/pL1 & Full-length clpL1ORF cloned into pKT25 & This study \\
\hline
\end{tabular}


TABLE 1 | Continued

\begin{tabular}{|c|c|c|}
\hline Strain or Plasmid & Relevant genotype or description & Source or reference \\
\hline pKT25-c/pL2 & Full-length c/pL2 ORF cloned into pKT25 & This study \\
\hline pKNT25-ctsR & Full-length ctsR ORF without stop codon cloned into pKNT25 & This study \\
\hline pKNT25-c/pC & Full-length clpC ORF without stop codon cloned into pKNT25 & This study \\
\hline pKNT25-c/pL1 & Full-length clpL 1 ORF without stop codon cloned into pKNT25 & This study \\
\hline pKNT25-c/pL2 & Full-length clpL2 ORF without stop codon cloned into pKNT25 & This study \\
\hline pUT18C-ctsR & Full-length ctsR ORF cloned into pUT18C & This study \\
\hline pUT18C-c/pC & Full-length clpC ORF cloned into pUT18C & This study \\
\hline pUT18C-c/pL1 & Full-length c/pL1 ORF cloned into pUT18C & This study \\
\hline pUT18C-c/pL2 & Full-length c/pL2 ORF cloned into pUT18C & This study \\
\hline pUT18-ctsR & Full-length ctsR ORF without stop codon cloned into pUT18 & This study \\
\hline pUT18-clpC & Full-length clpC ORF without stop codon cloned into pUT18 & This study \\
\hline pUT18-c/pL1 & Full-length clpL1 ORF without stop codon cloned into pUT18 & This study \\
\hline pUT18-c/pL2 & Full-length c/pL2 ORF without stop codon cloned into pUT18 & This study \\
\hline
\end{tabular}

van $^{r}$, vancomycin resistance; eryr, erythromycin resistance; $\mathrm{cm}^{r}$, chloramphenicol resistance; spec ${ }^{r}$, spectinomycin resistance; amp ${ }^{r}$, ampicillin resistance; kan $^{r}$, kanamycin resistance; tet ${ }^{R}$, tetracyclin resistance.

were harvested during late exponential phase $\left(\mathrm{OD}_{600}=0.8\right.$ corresponding to $1.10^{8} \mathrm{CFU} \cdot \mathrm{ml}^{-1}$ ) and directly transferred to $48^{\circ} \mathrm{C}$ for heat stress or into acidified FT80m medium ( $\mathrm{pH} 3.5$ ) then incubated at $28^{\circ} \mathrm{C}$ during $90 \mathrm{~min}$. Bacterial cultivability was estimated on FT80m agar plates $\left(\mathrm{CFU} \cdot \mathrm{ml}^{-1}\right.$ ) supplemented with relevant antibiotics. Growth was monitored in liquid culture by following $\mathrm{OD}_{600}$ over time.

Escherichia coli EC101 and C2992I were used as host strains for cloning and plasmid maintenance. Bacterial adenylate cyclase two-hybrid (BACTH) assays were carried out with the E. coli $c a^{-}$strain DHT1, kindly provided by MPSDM. E. coli strains were grown at $37^{\circ} \mathrm{C}$ (except $\mathrm{DHT} 1,28^{\circ} \mathrm{C}$ ) in Luria-Bertani (LB) medium supplemented with erythromycin $\left(250 \mu \mathrm{g} \cdot \mathrm{l}^{-1}\right)$, kanamycin $\left(50 \mu \mathrm{g} \cdot \mathrm{ml}^{-1}\right)$, or/and ampicillin $\left(100 \mu \mathrm{g} \cdot \mathrm{ml}^{-1}\right)$ when necessary.

Bacillus subtilis 168, ctsR-deficient QB4991 and derivative strains were grown at $37^{\circ} \mathrm{C}$ in $\mathrm{LB}$ medium supplemented with chloramphenicol $\left(5 \mu \mathrm{g} \cdot \mathrm{ml}^{-1}\right)$ and spectinomycin $\left(100 \mu \mathrm{g} \cdot \mathrm{ml}^{-1}\right)$ when required.

\section{DNA Manipulation and Bacterial Transformation}

Oenococcus oeni genomic DNA was extracted using the InstaGene ${ }^{\mathrm{TM}}$ Matrix (Bio-rad, Hercules, CA, United States), PCR amplifications for cloning constructions were performed with Expand High Fidelity PCR System (Roche, Meylan, France) and colony PCR amplifications were performed with GoTaq ${ }^{\circledR}$ DNA polymerase (Promega, Charbonnières-les-bains, France). Plasmids from E. coli were prepared using a GeneJET Plasmid Miniprep Kit (Thermo Fisher Scientific, Illkirch, France). PCR DNA fragments were purified with GeneJET PCR Purification Kit (Thermo Fisher Scientific). T4 DNA ligase and restriction endonucleases were purchased from New England Biolabs Inc. (NEB, Evry, France). Plasmids and ligation products were transferred by electroporation into E. coli strains (Taketo, 1988). Briefly, E. coli cells in early exponential phase $\left(\mathrm{OD}_{600}=0.5\right)$ were collected from $500 \mathrm{ml}$
LB culture, washed twice in $250 \mathrm{ml}$ of sterile ice-cold ultrapure water and concentrated 100 -fold in $10 \%$ glycerol. Aliquots of $0.1 \mathrm{ml}$ were mixed on ice with plasmid DNA or ligation mixture, and then submitted to an electroporation pulse of $25 \mu \mathrm{F}, 200 \Omega$, and $12.5 \mathrm{kV} / \mathrm{cm}$. After the pulse, cells were directly mixed with $1 \mathrm{ml}$ fresh LB medium, incubated for 20 to $40 \mathrm{~min}$ at $37^{\circ} \mathrm{C}$ and then plated on agar $\mathrm{LB}$ medium supplemented with suitable antibiotic. Plasmids were transferred by electroporation into O. oeni as previously described (AssadGarcía et al., 2008). O. oeni recombinant strains were selected on FT80m plates supplemented with erythromycin, vancomycin and lincomycin $\left(20 \mu \mathrm{g} \cdot \mathrm{ml}^{-1}\right.$ each). B. subtilis was transformed with recombinant vectors as previously described by Msadek et al. (1998). Transformants were selected on agar LB medium supplemented with suitable antibiotics.

\section{Plasmid Constructions and Cloning Strategy}

Plasmids and primers used in this study are respectively listed in Tables 1, 2.

The plasmid pSIPSYNASCtsR was constructed by inserting in reverse orientation the amplified full-length coding sequence of the O. oeni ctsR gene downstream from the synthetic $\mathrm{P}_{\mathrm{SYN}}$ promoter of plasmid pSIPSYN. The $c t s R$ gene was amplified by PCR from O. oeni ATCC BAA-1163 genomic DNA using ASCtsR3 and ASCtsR6 primers (Table 2) generating NcoI ( $3^{\prime}$ end of $c t s R$ ) and SmaI ( $5^{\prime}$-end of $\left.c t s R\right)$ restriction sites. The resulting plasmid named pSIPSYNASCtsR, carrying the complete coding sequence of the $c t s R$ gene in reverse orientation under the control of the synthetic PSYN promoter, was transferred by electroporation into O. oeni. The native PSIPSYN vector, without any insert, was introduced into $O$. oeni to serve as a control. The corresponding $O$. oeni recombinant strains were respectively designated by OoASctsR and Oosyn. The presence of the vector was confirmed by colony PCR amplification with specific primers Olcg303, olg302, or ASCtsR3. One colony was suspended in $50 \mu \mathrm{l}$ of lysis buffer (100 mM EDTA, [pH8], $20 \mathrm{mg} \cdot \mathrm{ml}^{-1}$ Proteinase K) 
TABLE 2 | Primers used in this study.

\begin{tabular}{|c|c|c|c|c|}
\hline Primer $^{1}$ & Sequence $\left(5^{\prime}-3^{\prime}\right)^{2,3}$ & $\begin{array}{l}\text { Plasmid construction and } \\
\text { function }\end{array}$ & $\begin{array}{l}\text { Restriction } \\
\text { site }\end{array}$ & $\begin{array}{l}\text { Source or } \\
\text { reference }\end{array}$ \\
\hline \multicolumn{5}{|c|}{ RNA silencing in $O$. oeni } \\
\hline ASctsR6 & GGGCCATGGCAGATGCTGTGTATTGATTATCCA & & Ncol & This study \\
\hline ctsR2 & CGGACTAAGCTITATCCATGAATGTITGTACTCT & $\begin{array}{l}\text { pXTCtsR25: O. oeni ctsR } \\
\text { coding sequence into pXT for } \\
\text { heterologous expression in } \\
\text { B. subtilis pETCtsR: O. oeni } \\
\text { CtsR production }\end{array}$ & Hindlll & This study \\
\hline Olcg20 & GCCCGAATTCTAAATTAATCGAAGCCTITTGAC & & EcoRl & \\
\hline Olcg302 & GGGCCATGGCAAATACCTCCTGATTCATTAATGCAGGGGTAC & $\begin{array}{l}\text { pSIPSYN: Synthetic promoter } \\
\text { PSYN amplification }\end{array}$ & Ncol & $\begin{array}{l}\text { (Darsonval } \\
\text { et al., 2016) }\end{array}$ \\
\hline Olcg303 & CCCAAGCTTGCGCAACTGTTGGGAAGGG & & HindllI & \\
\hline \multicolumn{5}{|c|}{ Over-expression in E. coli BL21 } \\
\hline Olcg1 & ATGCATGCCATGGCAGAAGCTAATATITCAG & $\begin{array}{l}\text { pETctsR : O. oeni ctsR } \\
\text { coding sequence into } \\
\mathrm{pET} 28 \mathrm{a}(+) \text { for overexpression } \\
\text { in E. coli BL21 }\end{array}$ & Ncol & This study \\
\hline Olcg2 & GGGCTCGAGTCCATGAATGTTTGTACTCTCA & & Xhol & \\
\hline hsp18N & GGGCCATGGCAAATGAATTAATGGATAGA & $\begin{array}{l}\text { pEThsp18: O. oeni hsp18 } \\
\text { coding sequence into } \\
\text { pET28a(+) for overexpression } \\
\text { in E. coli BL21 }\end{array}$ & Ncol & This study \\
\hline CtsR20 & GGTGGTCTCGAATTCTTATCCATGAATGTTTGTACTCTCAA & & EcoRl/Bsal & \\
\hline CtsR25 & AAGAAGCTTATTGATAGGAGGATCAAATTATGGCAGAAGCTAATA & $\begin{array}{l}\text { cts } R \text { coding sequence, } \\
\text { cts } R-T 18 \text { and } \\
\text { cts } R-T 25 \text { fusions }\end{array}$ & HindIII & This study \\
\hline CtsR22 & GGAGGATCCTCTCCATGAATGTTTGTACTCTCAA & & BamHI & \\
\hline ClpL1-21 & GGAGGATCCCGCTAATAATGATTATITAATAACAG & $\begin{array}{l}\text { clpL1 coding } \\
\text { sequence,T18-cts } R \text { and } \\
\text { T25-cts } R \text { fusions }\end{array}$ & $\mathrm{BamHI}$ & This study \\
\hline ClpL1-20 & CTCGAATTCTCACTTTCCAGTGATCTTAATTG & & EcoRl & \\
\hline ClpL1-23 & GGTGGTCTCAAGCTTATTGATAGGAGGATTCAATCATG & $\begin{array}{l}\text { c/pL1 coding sequence, } \\
\text { c/pL1-T18 and } \\
\text { clpL1-T25fusions }\end{array}$ & Hindlll/Bsal & This study \\
\hline ClpL1-22 & GGAGGATCCTCCTITCCAGTGATCTTAATTGTTC & & BamHI & \\
\hline ClpL2-21 & GGTGGTCTCGGATCCCGCTGATTATAATGACGATCCCT & $\begin{array}{l}\text { clpL2 coding sequence,T18- } \\
c / p L 2 \text { and } T 25-c / p L 2 \text { fusions }\end{array}$ & BamHl/Bsal & This study \\
\hline ClpL2-20 & GGTGGTCTCGAATTCTTAATTATCTIITTGATTCGTGGCGG & & EcoRl/Bsal & \\
\hline ClpL2-27 & GGTGGTCTCAAGCTTAGGAGGAGGAAAAAATGGCTGATTATAATGACGATCCCT & $\begin{array}{l}\text { c/pL2 coding sequence, } \\
\text { c/pL2-T18 and c/pL2-T25 } \\
\text { fusions }\end{array}$ & Hindlll/Bsal & This study \\
\hline
\end{tabular}


TABLE 2 | Continued

\begin{tabular}{|c|c|c|c|c|}
\hline Primer $^{1}$ & Sequence $\left(5^{\prime}-3^{\prime}\right)^{2,3}$ & $\begin{array}{l}\text { Plasmid construction and } \\
\text { function }\end{array}$ & $\begin{array}{l}\text { Restriction } \\
\text { site }\end{array}$ & $\begin{array}{l}\text { Source or } \\
\text { reference }\end{array}$ \\
\hline ClpL2-22 & GGTGGTCTCGGATCCTCATTATCTIITGATTCGTGGCGG & & BamHI/Bsal & \\
\hline ClpC21 & GGTGGTCTCCTGCAGGATAATCAATACACAGCATCTG & $\begin{array}{l}\text { clpC coding sequence, } \\
\text { T25-clpC fusions }\end{array}$ & Pstl & This study \\
\hline ClpC20 & GGTGGTCTCTCTAGATTATITGTACTIITCAATTGGTG & & Xbal & \\
\hline ClpC21C & GGTGGTCTCC्CTGCAGCGATAATCAATACACAGCATCTG & $\begin{array}{l}\text { clpC coding sequence (with } \\
\text { clpC20), T18-c/pC fusions }\end{array}$ & Pstl & This study \\
\hline ClpC21KT & GGTGGTCTCCTGCAGCCGATAATCAATACACAGCATCTG & $\begin{array}{l}\text { clpC coding sequence (with } \\
\text { clpC20), T25-c/pC fusions }\end{array}$ & Pstl & This study \\
\hline ClpC27 & CCCAAGCTIAGGAGGAAACATTCATGGATAATCAATACACAGCATCTG & $\begin{array}{l}\text { clpC coding sequence, } \\
\text { c/pC-T18 and c/pC-T25 } \\
\text { fusions }\end{array}$ & HindIIII & This study \\
\hline ClpC24 & GGTGGTCTCCTGCAGTCTITGTACTIITCAATITGGTG & & Pstl & \\
\hline
\end{tabular}

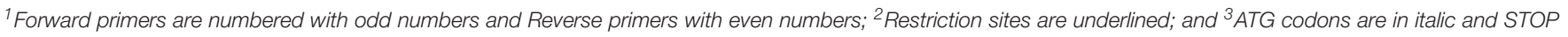
codon appears in bold.

and then mixed by vortex. The resulting mix was heated $15 \mathrm{~min}$ at $65^{\circ} \mathrm{C}$ then $5 \mathrm{~min} 95^{\circ} \mathrm{C}$ and $5 \mu \mathrm{l}$ of this mix were used as a DNA template in the PCR mix.

The pET28a $(+)$ plasmid (Novagen, VWR International S.A.S, Fontenay-sous-Bois, France) was used for $c s t R$ and $h s p 18$ overexpression in E. coli BL21 $\lambda$ (DE3) strain. The ctsR and $h s p 18$ coding sequences were amplified by PCR using primer pairs olcg1 and olcg2 and hsp18N and hsp18S, respectively. PCR products were respectively cloned between the NcoI and XhoI sites and the NcoI and SacI sites of pET28a $(+)$. The resulting plasmids, $\mathrm{pET} c t s R$ and $\mathrm{pEThsp18}$, were then introduced into in E. coli BL21 $\lambda$ (DE3) by electroporation.

The pXT integrative plasmid was used to express the O. oeni cstR in the B. subtilis $\Delta c t s R$ mutant strain (Derré et al., 2000). The full-length coding sequence was amplified by PCR from O. oeni ATCC BAA-1163 genomic DNA using primers CtsR2 and CtsR5 (Table 2). The PCR-generated fragment was cloned between the BamHI and HindIII sites of plasmid pXT under the control of a xylose inducible promoter $\left(\mathrm{P}_{\mathrm{xylA}}\right)$. The resulting plasmid, pXTCtsR25, was integrated at the B. subtilis thrC locus of the $\Delta c t s R$-hsp18'-OoctsR strain, corresponding to the $\Delta c t s R$ mutant strain (QB4991) carrying a transcriptional fusion between the promoter region of the O. oeni hsp18 gene and the bgaB gene of Geobacillus stearothermophilis ( $\mathrm{pDL}$ hsp18 $\rightarrow$ QB4991) (Grandvalet et al., 2005). The recombinant strains were first selected for resistance to spectinomycin and screened for susceptibility to erythromycin and colony PCR amplifications were performed with primers CtsR2 and CstR5 to confirm successful chromosomal integration.

To construct recombinant plasmids used in the BACTH complementation assays, genes coding for the O. oeni proteins were amplified by PCR using appropriate primers pairs (Table 2) and genomic DNA from O. oeni ATCC BAA-1163 as the template. The resulting PCR products were cloned between the $B a m \mathrm{HI}$ and EcoRI sites of the pKT25 and pUT18C vectors (except for the $c l p C$ gene, cloned between the Pst I and XbaI sites). The resulting plasmids expressed hybrid proteins, in which the proteins of interest were fused to the C-terminus of the T25 or T18 fragment of adenylate cyclase (AC) from Bordetella pertussis.
For the reciprocal combinations, PCR-generated fragments (without the stop codon, see Table 2) were digested with appropriate enzymes and cloned between the HindIII and BamHI sites of the pKNT25 and pUT18 vectors (except for $c l p C$ which was cloned between the HindIII and PstI sites). This second set of recombinant plasmids expressed hybrid proteins in which the proteins of interest were fused to the N-terminus of the T25 or T18 fragment of AC.

\section{DNA Sequencing and Sequence Analysis}

Nucleotide sequences of recombinant vector inserts were verified on both strands by nucleotide sequencing with labeling and capillary separation on the AB3730xl performed by GeneWiz ${ }^{\circledR}$ Europe (Essex, United Kingdom). Nucleotide sequencing results were analyzed using Clustal Omega software ${ }^{2}$.

\section{Production and Purification of CtsR and CtsR Polyclonal Antibody Production}

CtsR was purified from E. coli BL21-CtsR strain, as described previously (Assad-García et al., 2008). Briefly, E. coli BL21CtsR was grown aerobically in LB medium supplemented with $50 \mu \mathrm{g} \cdot \mathrm{ml}^{-1} \mathrm{kanamycin}$ at $37^{\circ} \mathrm{C}$ until $\mathrm{OD}_{600}=0.7-1$. Isopropyl$\beta$-D-thiogalactopyranoside (IPTG, $1 \mathrm{mM}$ ) was added to the culture to induce recombinant CtsR synthesis. After $15 \mathrm{~h}$ aerobic incubation $(150 \mathrm{rpm})$ at $21^{\circ} \mathrm{C}$, cells were harvested by centrifugation $(6,500 \times g$ for $10 \mathrm{~min})$. The pellet was suspended in cold lysis buffer $\left(50 \mathrm{mM} \mathrm{Na}_{2} \mathrm{HPO}_{4} / \mathrm{NaH}_{2} \mathrm{PO}_{4}\right.$ [pH 8], $300 \mathrm{mM}$ $\mathrm{NaCl}$ ) and disrupted in a constant cell disruption system (CellD, Constant Systems Ltd., Roquemaure, France) with glass beads $(0.5 \mu \mathrm{m})$. The suspension was centrifuged at $6,300 \times g$ for $20 \mathrm{~min}$ at $4^{\circ} \mathrm{C}$ to remove unbroken cells and cell debris. The supernatant was loaded onto a 1-ml Ni-Nitrilotriacetic acid column (Qiagen, Courtaboeuf, France) equilibrated with lysis buffer. The column was washed 10 times with 1 column volume of lysis buffer supplemented with $20 \mathrm{mmol} \cdot \mathrm{1}^{-1}$ imidazole. The recombinant CtsR protein was then eluted with lysis buffer supplemented with $250 \mathrm{mmol} \cdot \mathrm{l}^{-1}$ imidazole. The eluate

\footnotetext{
${ }^{2}$ https://www.ebi.ac.uk/Tools/msa/clustalo/
} 
was dialyzed against lysis buffer and protein purification was monitored by sodium dodecylsulfate-polyacrylamide gel electrophoresis (SDS-PAGE, 12.5\% polyacrylamide) as described by Laemmli (1970). Polyclonal antibodies were obtained by direct immunization of SPF-rabbits with purified CtsR protein (Eurogentec, Liège, Belgium). Antiserum was used for CtsR immunodetection.

\section{Whole Cell Extracts and Western Blotting}

Oenococcus oeni Lo18 and CtsR protein levels were detected using rabbit antiserum raised against Lo18 (laboratory stock) or CtsR (obtained as described above). In both cases, the pellet from $50 \mathrm{ml}$ of culture was washed twice in saline $\left(9 \mathrm{~g} \cdot \mathrm{l}^{-1} \mathrm{NaCl}\right)$ and adjusted to $30 \mathrm{OD}$ Unit $\cdot \mathrm{ml}^{-1}$ in lysis buffer $(10 \mathrm{mM}$ Tris$\mathrm{HCl}$ [pH 8]). Cells were disrupted by two consecutive treatments using a Precellys homogenizer with glass beads $(0.5 \mu \mathrm{m})$ at $6,500 \times g$ (Precellys, Paris, France; $60 \mathrm{~s}-20 \mathrm{~s}$ pause-60 s). The suspension was centrifuged at $13,200 \times g$ for $15 \mathrm{~min}$ at $4^{\circ} \mathrm{C}$ to remove unbroken cells and cellular debris. Supernatants containing total cellular proteins were collected and assayed with Bio-rad Protein Assay Dye Reagent Concentrate (Bio-Rad) with bovine serum albumin as the standard. Total cellular proteins (15 $\mu \mathrm{g}$ ) were mixed with loading buffer 5X (250 mM Tris$\mathrm{HCl}$ [pH 8], 50\% glycerol, $77 \mathrm{~g} \cdot \mathrm{l}^{-1} \mathrm{DTT}, 0.4 \%$ bromophenol blue, $10 \% \mathrm{SDS}$ ), heated $5 \mathrm{~min}$ at $85^{\circ} \mathrm{C}$ and separated by SDSPAGE (17\% polyacrylamide). Proteins were then transferred on a nitrocellulose membrane (BioRad, Les Ulis, France) using a Trans-Blot Turbo (BioRad). The membrane was saturated in blocking buffer (1X PBS, 0.2\% Tween ${ }^{\circledR} 20$ and 5\% Bovine Serum Albumin, BSA) and hybridized in blocking buffer with rabbit antiserum, containing polyclonal antibodies directed against O. oeni Lo18 $(1: 1,000)$ or CtsR $(1: 1,000)$, for one night at room temperature with gentle shaking. The membrane was then washed three times for $5 \mathrm{~min}$ in $1 \mathrm{X}$ PBS-T $\left(0.2 \%\right.$ Tween $\left.{ }^{\circledR} 20\right)$ and incubated one hour at room temperature with conjugated fluorophore IRDye 680LT goat anti-rabbit antibodies (1:10,000, LiCor $^{\circledR}$, Biosciences-GmbH) in blocking buffer. The membrane was washed again in $1 \mathrm{X}$ PBS-T at room temperature three times for $5 \mathrm{~min}$. Detection was performed with Odyssey Fc Western Blot Imaging System (LiCor ${ }^{\circledR}$ Biosciences-GmbH).

\section{$\beta$-Galactosidase Assays in B. subtilis}

Overnight cultures of $B$. subtilis grown in LB medium supplemented with chloramphenicol $\left(5 \mu \mathrm{g} \cdot \mathrm{ml}^{-1}\right)$ were diluted to $\mathrm{OD}_{600}=0.05$ in fresh $\mathrm{LB}$ medium and grown at different temperatures 28,37 , or $42^{\circ} \mathrm{C}$ under aerobic conditions (140 rpm). At the mid-exponential phase $\left(\mathrm{OD}_{600}=1.5\right)$, xylose was added at a final concentration of $20 \mathrm{mM}$ to induce $c t s R$ gene expression during $12 \mathrm{~h}\left(\mathrm{DO}_{600}=3\right)$. For each sample, $\beta$-galactosidase activity was determined as previously described (Miller, 1972; Grandvalet et al., 2005) and expressed as Miller units per mg cellular protein. Protein concentrations were determined using the Bio-Rad protein assay. Experiments were performed three times on three independent cultures.

Repression of $h s p 18^{\prime}-$ bgaB expression by CtsR was tested at six different temperatures by following $\beta$-galactosidase activity
LB agar plates supplemented with 5-bromo-4-chloro-3-indolyl$\beta$-D-galactopyranoside (X-Gal), with $20 \mathrm{mM}$ xylose to induce expression of the O. oeni ctsR gene. Strains were plated in parallel with incubation at six different temperatures: $28,33,35,37,42$, and $50^{\circ} \mathrm{C}$.

\section{BACTH Assays}

For BACTH assays, recombinant vectors (pKT25, pKNT25, pUT18C, and pUT18) carrying the studied O. oeni genes were co-transformed in all possible combinations into E. coli DHT1 cells (Dautin et al., 2000). Co-Transformants were plated on LB agar medium supplemented with $40 \mu \mathrm{g} \cdot \mathrm{ml}^{-1} \mathrm{X}-\mathrm{Gal}$ and $0.5 \mathrm{mM}$ IPTG (isopropylthio- $\beta$-galactoside) and incubated at $28^{\circ} \mathrm{C}$ for 24 to $36 \mathrm{~h}$. Interaction efficiencies between different hybrid proteins were quantified by measuring $\beta$-galactosidase activity in a 96-well microtiter plate after cell permeabilization. For each co-transformation combination, six independent clones were tested. E. coli co-transformed clones were grown in $300 \mu \mathrm{l}$ LB broth supplemented with $0.5 \mathrm{mM}$ IPTG, $50 \mu \mathrm{g} \cdot \mathrm{ml}^{-1}$ kanamycin and $100 \mu \mathrm{g} \cdot \mathrm{ml}^{-1}$ ampicillin in $5 \mathrm{ml}$ hemolysis tube and then incubated at $28^{\circ} \mathrm{C}$ for 16 to $24 \mathrm{~h}$ under aerobic conditions (150 rpm). Cultures were diluted 1:5 into M63 medium (Sambrook et al., 1989) into a final volume of $200 \mu \mathrm{L}$ and $\mathrm{OD}_{595}$ was measured by GENios reader (Tecan, Lyon, France). Cell suspensions were replaced by LB medium diluted 1:5 into M63 medium for control wells. Cells were permeabilized by adding $7 \mu \mathrm{l}$ SDS $(0.05 \%, w / v)$ and $10 \%$ chloroform per well with vigorous mixing with a multichannel pipette and incubated 30 to $40 \mathrm{~min}$ at room temperature. For enzymatic assays, $20 \mu \mathrm{l}$ of permeabilized cells were added to $105 \mu \mathrm{l}$ of reaction mixture: $70 \mathrm{mM} \mathrm{Na} \mathrm{HPO}_{4}, 30 \mathrm{mM} \mathrm{NaH} \mathrm{PO}_{4}, 1 \mathrm{mM} \mathrm{MgSO}$, 0,2 $\mathrm{mM} \mathrm{MnSO}_{4}$ [pH7.0], $100 \mathrm{mM} \beta$-mercaptoethanol and 0.1\% ONPG (o-nitrophenyl- $\beta$-D-galactopyranoside). After $30 \mathrm{~min}$ at room temperature, $\mathrm{OD}_{405}$ was measured using a GENios reader (Tecan). Enzymatic activities, $A$, were calculated in relative units using the following formula:

$$
A_{r \cdot u}=1,000 \times \frac{\left(\mathrm{OD}_{405}-\mathrm{OD}_{405_{\text {control well }}}\right)}{\left(\mathrm{OD}_{595}-\mathrm{OD}_{\left.595_{\text {control well }}\right)}\right.} / \text { Incubation time }_{\text {min }}
$$

\section{Statistical Analysis}

The significance of the difference among percentage of cultivability values was determined by a two-tailed Student $t$-test. The confidence interval for a difference in the means was set at 95\% $(P \leq 0.05)$ for all comparisons.

\section{RESULTS}

\section{Antisense RNA Approach in O. oeni to Characterize CtsR Function in vivo}

The antisense RNA approach is the only method currently available to modulate gene expression in O. oeni (Darsonval et al., 2016). Investigation of $c t s R$ gene function in O. oeni was therefore performed by producing antisense RNA (asRNA) targeting ctsR mRNA. O. oeni was transformed with the recombinant plasmid encoding asRNA targeting the full-length $c t s R$ mRNA 
(pSIPSYNASctsR), and the empty control plasmid (pSIPSYN), giving strains OoASctsR and Oosyn, respectively. In order to validate the efficiency of this asRNA approach, the effect of ASctsR RNA production was examined at the protein level by immunodetection of Lo18 (Figure 1). Lo18 is a well-studied small Hsp encoded by $h s p 18$, chosen as a representative of CtsR regulon expression. Under optimal growth-conditions, Lo18 is not detected in the wild type strain ATCC BAA-1163 and the recombinant strain Oosyn, carrying the control plasmid, due to repression by CtsR. Consistent with this observation, Lo18 is detected after heat stress in both strains, indicating that the CtsR-dependant stress response regulation is functional in these conditions (Figure 1). In OoASctsR, Lo18 protein is detected in both conditions, with and without thermal stress. This observation indicates derepression of CtsR-controlled genes in the absence of heat stress due to the production of ASctsR RNA. Protein bands with an apparent molecular mass smaller than Lo18 are detected in both OoASctsR and E. coli overexpressing the $h s p 18$ gene. These correspond to truncated forms of Lo18 as previously reported by Coucheney et al. (2005a).

Since this antisense RNA approach leads to derepression of the CtsR regulon, we tested survival of the bacteria following stress treatment (Figure 2). No loss of cultivability was observed for the
Oosyn control strain 90 min after temperature shifting from 28 to $48^{\circ} \mathrm{C}$ (Figure 2A) or a shift in $\mathrm{pH}$ from 5.3 to 3.5 (Figure 2B). In contrast, $56 \%$ of the OoASCtsR cells are lost following heat stress (Figure 2A) and $58 \%$ after pH 3.5 acid stress (Figure 2B). This result suggests that derepression of the CtsR regulon in the absence of stress interferes with cell survival under stress conditions, indicating that CtsR plays a key role in the O. oeni stress response.

\section{CtsR of O. oeni Represses hsp18 Expression}

Bacillus subtilis was used as a tool for the functional analysis of O. oeni CtsR. The B. subtilis QB4991 $\Delta c t s R$ mutant strain (Derré et al., 1999) was used to express the O. oeni ctsR gene in single copy from a xylose-inducible promoter (strain QB4991XTOoctsR; see Materials and Methods). In order to assess the functionality of $O$. oeni CtsR in $B$. subtilis, a transcriptional fusion between the promoter region of $O$. oeni $h s p 18$ and the $\operatorname{bgaB}$ thermostable $\beta$-galactosidase gene ( $h s p 18^{\prime}$-bgaB) was integrated in single copy in the B. subtilis wild type and QB4991-XTOoctsR strains, respectively designated WT and $\Delta c t s R$-XTOoctsR.

Expression of the O. oeni CtsR protein in B. subtilis was verified by Western blot (Figure 3). B. subtilis wild-type (WT),

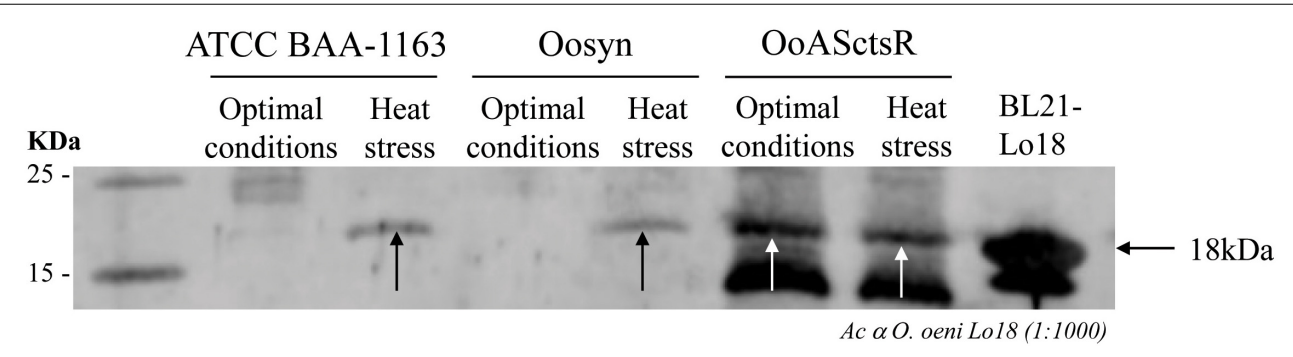

FIGURE 1 | Immunodetection of Lo18 in O. oeni wild type strain (ATCC BAA-1163) and recombinant strains carrying the control pSIPSYN plasmid (Oosyn) or pSIPSYNASctsR plasmid allowing expression of asRNA targeting ctsR (OoASctsR) were cultivated at $28^{\circ} \mathrm{C}$ in $\mathrm{FT} 80 \mathrm{~m}$ medium up to the end of the exponential growth phase. Total cellular proteins were extracted immediately $\left(28^{\circ} \mathrm{C}\right)$ or following a sub-lethal thermal treatment $\left(30\right.$ min at $\left.42^{\circ} \mathrm{C}\right)$. For each strain and each condition, $15 \mu \mathrm{g}$ of protein were separated by SDS-PAGE. The O. oeni Lo18 protein was detected by immunodetection with polyclonal antibodies directed against Lo18 and anti-rabbit antibodies conjugated with IRDye 680LT fluorophore (LiCor ${ }^{\circledR}$ ) as secondary antibody. Total protein extract from E. coli BL21 $\lambda$ DE3 carrying pEThsp18 plasmid was used as a positive control (BL21-Lo18).
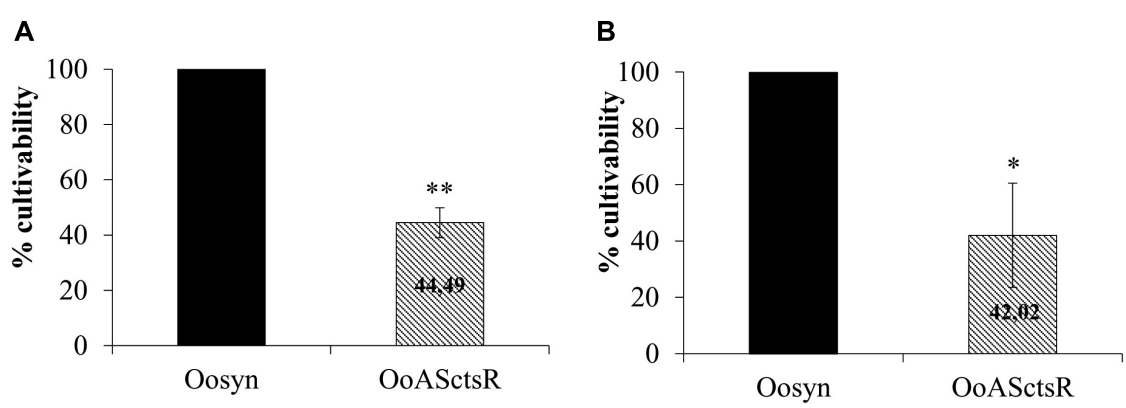

FIGURE 2 | Cell cultivability following stress treatment. Recombinant strains carrying the control empty vector (Oosyn; black bars) or plasmid with asRNA targeting ctsR (OoASctsR; hatched bars) were grown at $28^{\circ} \mathrm{C}$ until mid-exponential phase. Cultures were transferred to $48^{\circ} \mathrm{C}(\mathbf{A})$ or into acidified $\mathrm{FT} 80 \mathrm{~m}$ medium (pH 3.5$)$ (B). Cultivability was estimated on agar plates (CFU $\cdot \mathrm{ml}^{-1}$ ) after 90 min treatment. After CFU counting on agar plates, the cultivability rate is calculated by dividing the number of cells following treatment by total number of cells before stress treatment, normalized to the reference strain Oosyn set at $100 \%$. Significant differences are based on a unilateral and paired $t$-test $\left({ }^{*} P<0.005 ;{ }^{*} P<0.05\right)$. 


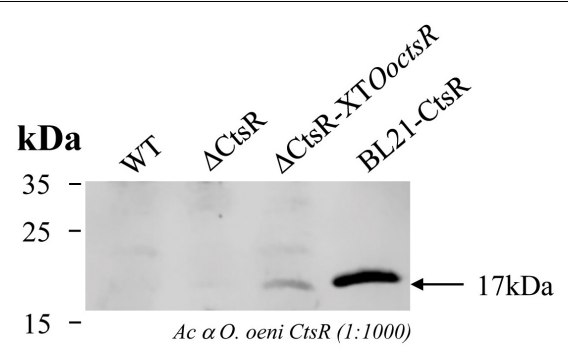

FIGURE 3 | Immunodetection of the O. oeni CtsR protein in B. subtilis. B. subtilis wild-type $(\mathrm{WT})$, ctsR-deficient $(\Delta c t s R)$ and $c t s R$-deficient expressing the $O$. oeni ctsR gene ( $\Delta$ ctsR-XTOocts $R$ ) strains were grown at $28^{\circ} \mathrm{C}$ in LB medium and xylose $(20 \mathrm{mM})$ was added at the mid-exponential growth phase $\left(\mathrm{OD}_{600}=1.5\right)$. Cells were harvested $12 \mathrm{~h}$ after adding xylose and total cellular proteins were extracted and analyzed by Western blot using polyclonal antibodies directed against CtsR from 0 . oeni and anti-rabbit antibodies conjugated with IRDye 680LT fluorophore $\left(\right.$ LiCor $\left.^{\circledR}\right)$ as secondary antibody. Total protein extract from E. coli BL21 carrying pETctsR plasmid (BL21-CtsR) strain was used as a positive control.

$\Delta c t s R$ mutant $(\Delta c t s R)$ and $\Delta c t s R$ mutant with the xyloseinducible O. oeni $c t s R$ gene ( $\Delta c t s R$-XTOoctsR) strains were grown at $28^{\circ} \mathrm{C}$ in $\mathrm{LB}$ with xylose added in the mid-log phase. No signal was detected in whole cell extracts from the wild type or $\Delta c t s R$ mutant strains whereas a band with a $17 \mathrm{kDa}$ apparent molecular mass, corresponding to that of the CtsR positive control (BL21CtsR), was detected in the strain carrying the $O$. oeni ctsR gene under the control of PxylA promoter, confirming correct heterologous expression.

Expression of the $h s p 18^{\prime}-$ bgaB fusion in B. subtilis strain $\Delta c t s R$-XTOoctsR was followed by $\beta$-galactosidase activity assays during growth at $28^{\circ} \mathrm{C}$ in $\mathrm{LB}$ broth medium with or without xylose. In the absence of xylose, the $h s p 18^{\prime}-b g a B$ fusion is strongly expressed (approximately 350,000 Miller units $\cdot \mathrm{mg}^{-1}$ ). In the presence of xylose, expression of the $h s p 18^{\prime}-b g a B$ fusion is repressed more than 10 -fold (34,000 Miller units $\left.\cdot \mathrm{mg}^{-1}\right)$. Taken together, these results indicate that the $O$. oeni CtsR repressor is fully functional in B. subtilis and acts as a repressor of $h s p 18$ expression.

\section{CtsR of Oenococcus oeni Acts as a Thermosensor}

As previously suggested by Derré et al. (2000) and confirmed in L. lactis, G. stearothermophilus, and B. subtilis by Elsholz et al. (2010), CtsR is an intrinsic heat sensor with a species-specific temperature threshold. We tested thermoinduction of $h s p 18$ by O. oeni CtsR using B. subtilis as a heterologous host. Expression of hsp 18'-bgaB was followed by measuring $\beta$-galactosidase activities of the wild type (WT) and $\Delta c t$ s-XTOoctsR B. subtilis strains during growth at different temperatures $(28,33,35,37,42$, and $50^{\circ} \mathrm{C}$ ) with blue/white screening on X-Gal containing LB-agar plates with or without added xylose (Figure 4). White colonies correspond to the transcriptional repression of the $h s p 18^{\prime}$-bgaB fusion by CtsR. Blue colonies indicate thermoinduction of $h s p 18^{\prime}-$ bgaB expression following CtsR inactivation. We have previously shown that CtsR of B. subtilis is able to repress expression of
O. oeni hsp18 (Grandvalet et al., 2005). As expected, in wildtype B. subtilis strain (Figure 4, lane [1], WT), the CtsR regulator is active and represses $h s p 18^{\prime}-b g a B$ expression during growth at temperatures ranging from 28 to $42^{\circ} \mathrm{C}$. Following incubation at $50^{\circ} \mathrm{C}$, expression of $h s p 18^{\prime}-b g a B$ is induced due to inactivation of CtsR. As previously reported, these results confirm that the B. subtilis CtsR is active at temperatures up to $42^{\circ} \mathrm{C}$ (Elsholz et al., 2010). In the strain expressing O. oeni CtsR ( $\Delta c t s R$ $\mathrm{XTOoctsR}$ ), $h s p 18^{\prime}-$ bgaB is expressed at all growth temperatures in the absence of xylose, (Figure 4, lane [2]) due to absence of CtsR repression. When the $O$. oeni $c t s R$ gene is expressed by adding xylose (Figure 4, lane [3] $\Delta c t s R$-XTOoctsR+ Xylose) the $h s p 18^{\prime}-b g a B$ fusion is repressed during growth at $28^{\circ} \mathrm{C}$. However, repression by $\mathrm{O}$. oeni $\mathrm{CtsR}$ no longer occurs during growth at all temperatures tested above $28^{\circ} \mathrm{C}\left(33,35,37,42\right.$, and $\left.50^{\circ} \mathrm{C}\right)$ indicating that $\mathrm{O}$. oeni $\mathrm{CtsR}$ is active at $28^{\circ} \mathrm{C}$, the optimal growth temperature for $\mathrm{O}$. oeni, and totally inactive at $33^{\circ} \mathrm{C}$ and above. These results strongly indicate that the O. oeni CtsR transcriptional repressor is an intrinsic heat sensor with a specific temperature threshold adapted to the natural habitat of $O$. oeni.

\section{BACTH Analysis of CtsR/CIpL1/CIpL2/ClpC Interactions}

In order to understand the potential protein interaction network involved in regulation of CtsR activity in $O$. oeni, we used the BACTH technique. This approach is based on the interactionmediated reconstruction of a cyclic AMP (cAMP) signaling pathway in E. coli. Candidate proteins are produced as translational fusions with two fragments (T25 and T18) of the catalytic domain of Bordetella pertussis Adenylate Cyclase (AC) in an E. coli DHT1 cya- AC-deficient strain (Karimova et al., 1998). Upon interaction of the hybrid proteins, AC activity is restored due to the spatial proximity of the T25 and T18 fragments, leading to cAMP synthesis and transcriptional activation of catabolic operons such as the well-known lactose operon.

To characterize physical interactions, the four proteins (CtsR, ClpL1, ClpL2, and ClpC) were methodically tested for pairwise interactions using the BACTH complementation assay. The DNA sequences encoding the proteins of interest were cloned into appropriate BACTH vectors to generate hybrid proteins fused either at the N-terminal (pKT25 or pUT18C) or C-terminal extremities (pKNT25 or pUT18) of either the T25 or the T18 fragment of the B. pertussis AC (see Materials and Methods). To analyze putative physical associations between the resulting hybrid proteins, the E. coli DHT1 $\mathrm{cya}^{-}$strain was cotransformed with pairs of recombinant plasmids (Table 1) expressing the T25 and the T18 hybrid proteins (pKT25/pUT18C, pKT25/pUT18, pKNT25/pUT18C, or pKNT25/pUT18). The efficiency of functional complementation between the different hybrid proteins was determined by $\beta$-galactosidase assays and the results of the different pairwise combinations are summarized in Table 3.

Based on the characteristic features of CtsR and ClpATPases in the Firmicute phylum, we would anticipate homodimerization of CtsR and the oligomerization of the three ClpATPases. As expected, self-interaction of CtsR is seen with the four 


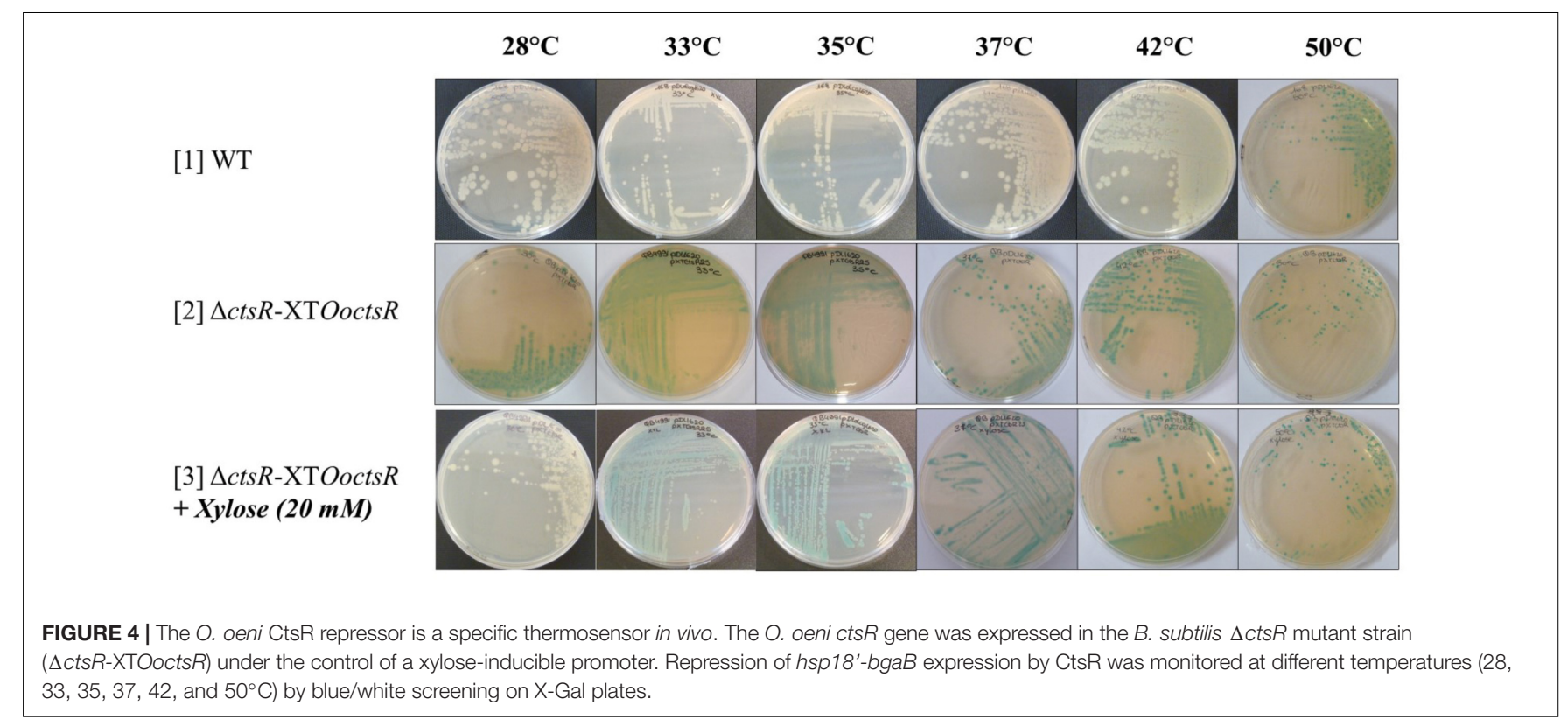

combinations of the hybrid proteins with $\beta$-galactosidase activities ranging from 203 to 458 units (Table 3). The BACTH analysis data also confirmed self-association of the ClpL1 and ClpC ATPases, but for ClpL2 self-association was less obvious. Among the four pairwise combinations of the hybrid proteins, a single one led to $\beta$-galactosidase activity indicating a possible self-association, but reaching only 54 units. These observations suggest either weak physical interactions or that ClpL2 may require additional partners to form proper oligomers.

The BACTH results suggest that $\mathrm{ClpC}$ is likely to form symmetric homo-oligomers. Indeed, the ClpC-T25 hybrid protein, in which $\mathrm{ClpC}$ is C-terminally fused with $\mathrm{T} 25$, interacts efficiently with the ClpC-T18 hybrid protein, with a free ClpC $\mathrm{N}$-terminus (140 units) but not with T18-ClpC (49 units).

Our analysis also revealed that the CtsR repressor associates with ClpL1. For CtsR and ClpL1, four out of eight possible pairwise combinations of the hybrid proteins led to $\beta$-galactosidase activities ranging from 62 to 92 units, indicating efficient physical interaction between these two proteins.

The BACTH analysis also highlights that ClpL1 is also able to interact with ClpL2. As shown in Table 3, T25-ClpL2 associates with T18-ClpL1, leading to $\beta$-galactosidase levels 10 times higher than with ClpL1-T18 (111 and 11 units, respectively) suggesting a possible symmetric hetero-oligomer formation. Taken together, these results suggest that ClpL1 may play a crucial role in regulation of CtsR activity during stress response in $O$. oeni.

\section{DISCUSSION}

Due to poor transformability and the lack of efficient genetic tools, $O$. oeni is not readily genetically tractable. Directed mutagenesis in $O$. oeni remains impossible to date and little is known about its genetic regulatory mechanisms. The asRNA production approach is presently the only approach to investigate stress response in this bacterium (Darsonval et al., 2016). By targeting ctsR for knockdown, we undertook an in vivo approach with the aim of broadening our knowledge on O. oeni CtsR, the only stress response regulator described to date. In this work, ctsR inhibition by asRNA affects expression of ctsR regulon genes leading to derepression under optimal growth conditions, as shown by an increased Lo18 protein levels at $28^{\circ} \mathrm{C}$ (Figure 1). This confirms for the first time in vivo CtsRdependent regulation of $h s p 18$ gene expression in O. oeni. We also highlighted that expression of a complementary asRNA targeting the full-length of $c t s R$ mRNA reduced cultivability of $O$. oeni by $50 \%$ following sub-lethal temperature or acid stress exposure (Figure 2). Our data indicate that CtsR plays an essential role in the stress response process with a crucial involvement in coping with prolonged heat and acid stress. Regulation by CtsR may extend beyond a specific role in thermoprotection or acidtolerance since its inactivation in Lactobacillus plantarum leads to pleiotropic effects correlated with its obvious housekeeping function as a central stress response regulator in O. oeni (van Bokhorst-van de Veen et al., 2013). We show here that $c t s R$ inhibition conferred a heat- and acid-sensitive phenotype to the recombinant strain. Interestingly, we previously observed this phenomenon by inhibiting $h s p 18$ expression with the same RNA silencing approach (Darsonval et al., 2016). These results suggest that in LAB, stress response gene expression must be carefully fine-tuned: levels that are too low under stress conditions or too high under optimal conditions would be deleterious. Indeed, whereas in most Gram-positive bacteria described so far, $c t s R$ deletions lead to an increase in heat resistance and general stress tolerance (Nair et al., 2000; Chastanet et al., 2001; Karatzas and Bennik, 2002; Hüfner et al., 2007; Zotta et al., 2009), in L. plantarum, incubation at $40^{\circ} \mathrm{C}$ strongly inhibited the growth of the mutant strain without affecting the wild type (Fiocco et al., 2010). These unexpected acid- and heatsensitive phenotypes observed in O. oeni OoASCtsR (Figure 2), 
TABLE 3 | BACTH analysis of CtsR, ClpL1, ClpL2, and ClpC interactions ${ }^{1}$.

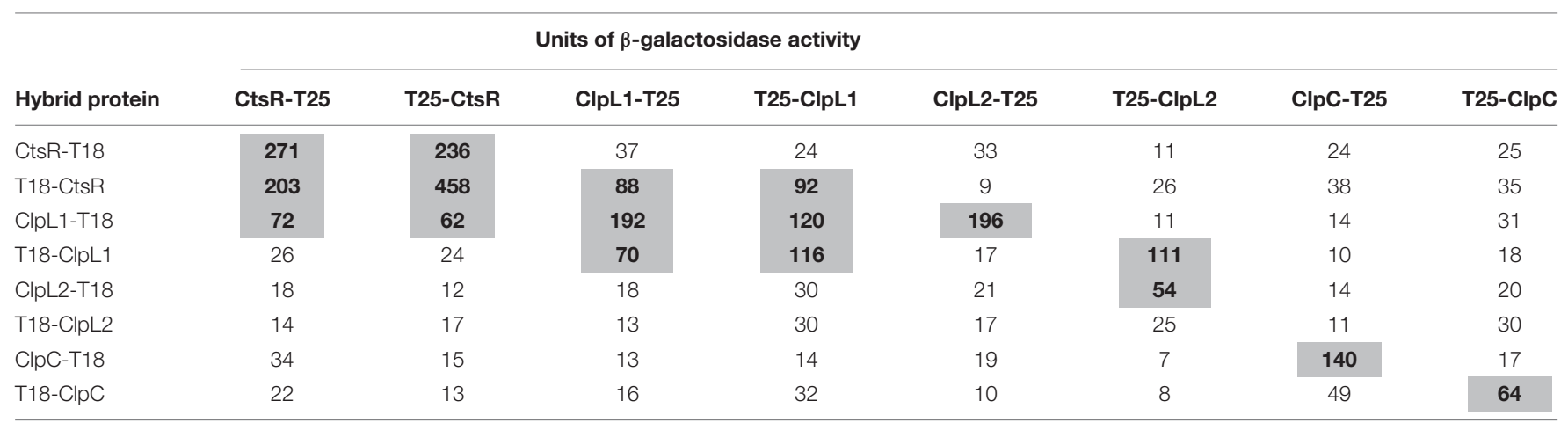

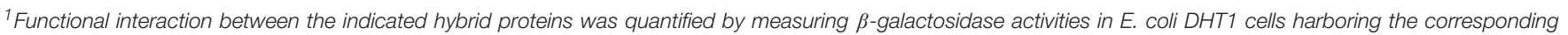

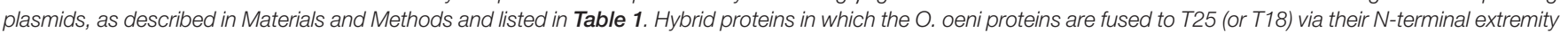

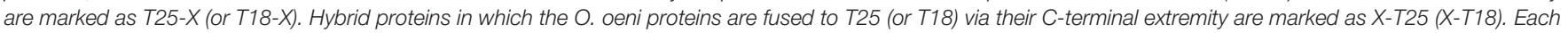

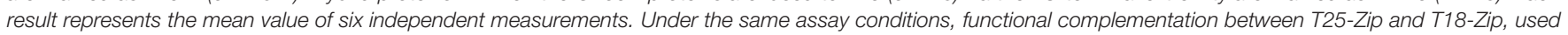

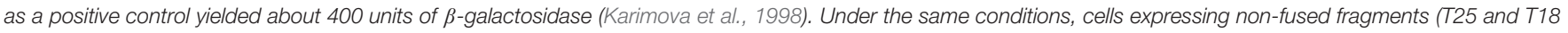

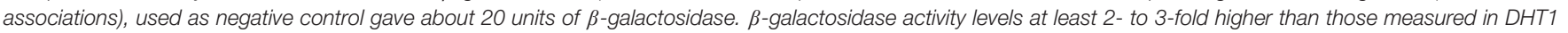
negative control cells are considered as effective protein-protein interactions and appear in bold and highlighted in gray.

are in agreement with the observation in L. plantarum, where inactivation of $c t s R$ causes derepression of $h s p$ genes including proteases and molecular chaperones. Excessive levels of Clp proteases and Hsp proteins would be detrimental to the cell, similar to the activity of the acyldepsipeptide antibiotic ADEP4 which has been shown to activate the ClpP protease, resulting in death of growing cells (Brötz-Oesterhelt et al., 2005). For example, accumulation of Lo18, known to be addressed to the membrane under environmental stress conditions, would provoke deleterious effects on physical state of the bacterial cell leading to a stress sensitive phenotype (Fiocco et al., 2010). Indeed, the heat-sensitive phenotype reported for the L. plantarum $\Delta c t s R$ mutant by Fiocco et al led to an intriguing impairment in the cell envelope (Fiocco et al., 2010). Taken together these results raise the possibility that CtsR might control other activities including cell envelope integrity. The partial impact on the cultivability observed suggests the involvement of other regulators of stress response that have not yet been described. In addition, modifications of $c t s R$ expression seem to have pleiotropic effects as observed in L. plantarum (Fiocco et al., 2010). Further studies will be needed to shed light on this aspect. In $O$. oeni, the combination of Lo18 immunelocalization by electron microscopy observation and fluorescence anisotropy could be considered to investigate the impact of CtsR regulon dysregulation on the cell wall and membrane integrity (Coucheney et al., 2005a; Darsonval et al., 2016). Our findings confirm that gene knockdown by antisense RNA is a powerful strategy to study the role of $O$. oeni genes in vivo. Obviously, even if this antisense RNA approach is currently the only available technique to modify gene expression in such a genetically intractable organism such as $O$. oeni, it is not a perfect solution.

We began studying the regulation of CtsR activity using B. subtilis and E. coli as heterologous hosts. In B. subtilis, thermo-induction of a $h s p 18^{\prime}-b g a B$ transcriptional fusion at different temperatures allowed us to show that CtsR can be inactivated in a temperature-dependent manner. These results are in agreement with Derré et al., 1999) and with results obtained in L. lactis, G. stearothermophilus, and B. subtilis by Elsholz et al. (2010) showing that CtsR is an in vivo intrinsic heat sensor with specific temperature thresholds according to the bacterial species. Indeed, CtsR-dependent gene expression is induced at temperatures above $42^{\circ} \mathrm{C}$ in L. lactis but repressed at temperatures up to $50^{\circ} \mathrm{C}$ in G. stearothermophilus (Elsholz et al., 2010). We show here that O. oeni CtsR-dependent gene expression is induced at growth temperatures of $33^{\circ} \mathrm{C}$ and above, acting as a molecular thermometer. CtsR sequences are highly conserved across the phylogenetic group of low-GC\% Grampositive bacteria. Two regions, the HTH and the winged HTH domains, are both conserved and crucial for CtsR activity, Derré et al., 2000) described two point mutants for B. subtilis CtsR (V16M and G65S), suppressing CtsR inactivation during heat stress, while Elsholz substituted the Glycine residue 64 by a proline at the tip of the hairpin in the highly conserved glycinerich loop of the CtsR winged HTH domain and showed that this residue is essential for B. subtilis CtsR activity in vivo and responsible for CtsR thermosensor ability in several low-GC\% Gram-positive bacteria (Derré et al., 2000; Fuhrmann et al., 2009; Elsholz et al., 2010). A piezotolerant strain of Listeria monocytogenes resistant to heat, acid and oxidative treatments had a single codon deletion in this conserved glycine-rich hairpin (Karatzas and Bennik, 2002; Karatzas et al., 2003). Nevertheless, while this glycine-rich domain appears to be responsible for CtsR thermosensitivity, it does not seem to be responsible for species-dependent temperature thresholds. Indeed, the glycinerich domain is highly conserved across Firmicutes (Derré et al., 1999). Differences in temperature thresholds may be due to the Hsp machinery specific to each species rather than the glycinerich region. Regulatory mechanisms of stress response genes have been well investigated in low-GC Gram-positive bacteria and revealed a diversity of actors involved in regulation of CtsR activity (Derré et al., 2000; Nair et al., 2000; Chastanet et al., 2003; Varmanen et al., 2003; Elsholz et al., 2010; Fiocco et al., 2010; Tao et al., 2012; Tao and Biswas, 2013). Namely, B. subtilis CtsR is 


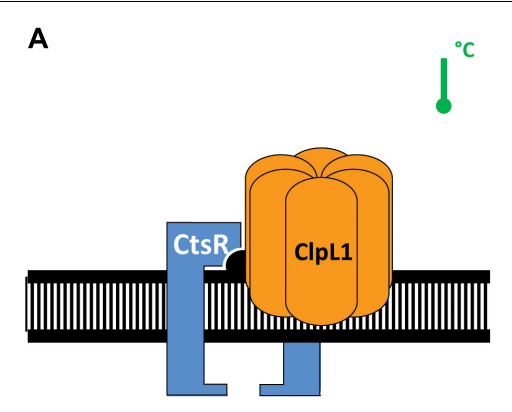

B

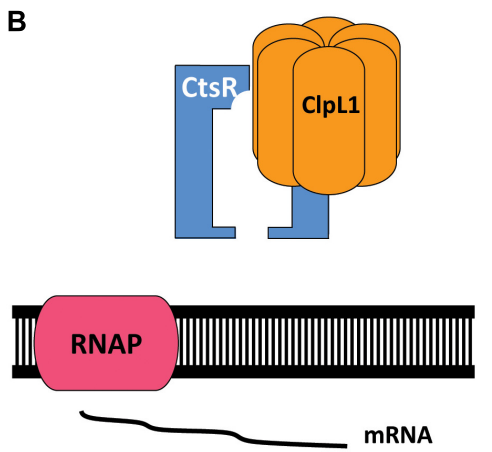

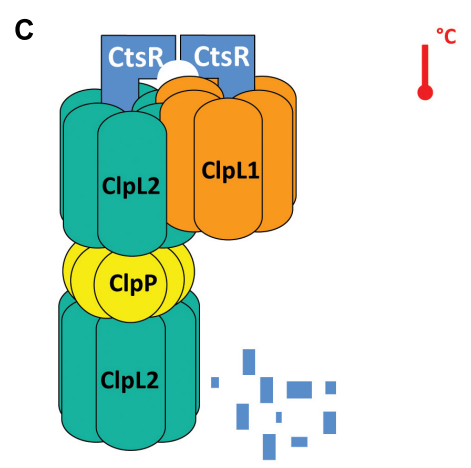

FIGURE 5 | Model for heat-dependent regulation of CtsR activity in O. oeni (adapted from Frees et al., 2007; Elsholz et al., 2010) During ideal conditions (depicted by the green thermometer), CtsR is most likely active as a dimer DNA-binding complex and binds to its operator sequences within the promoters of regulon members. ClpL1 binds CtsR to stabilize the regulator on its operator sequence (A). Upon heat exposure (temperature threshold $33^{\circ} \mathrm{C}$ ), represented by the red thermometer, CtsR undergoes a temperature-induced alteration of the winged HTH region that leads to dissociation of CtsR from the DNA (B). Consequently, transcription of the repressed genes is induced. Free CtsR is presumably addressed by ClpL1 (C) to the ClpL2P proteolytic complex for degradation, preventing CtsR aggregation. CtsR is then re-activated to repress transcription.

addressed to ClpCP by McsAB complex for degradation above $50^{\circ} \mathrm{C}$, whereas in L. lactis, ClpE replaces the McsB adaptator and addresses CtsR for degradation above $37^{\circ} \mathrm{C}$ while the $\mathrm{S}$. mutans CtsR is folded and stabilized by ClpL even at room temperature (Derré et al., 2000; Varmanen et al., 2003; Elsholz et al., 2010; Tao and Biswas, 2013). In O. oeni, the absence of ClpE, McsA and $\mathrm{McsB}$ orthologs may in part explain the difference in CtsR threshold temperature.

Our BACTH analysis indicates an interaction between ClpL1 and CtsR suggesting for the first time in the LAB the involvement of a ClpL family member in regulation of CtsR activity. These findings are consistent with the work of Tao and Biswas in S. mutans showing ClpL-CtsR interaction via the ClpL D2-small domain at the amino-terminal extremity, a domain conserved in the O. oeni ClpL1 sequence (Tao and Biswas, 2013). However, our BACTH analysis did not reveal an interaction between CtsR and ClpL2, which also carries a D2-small region. We noticed that ClpL2 could not form strong homo-oligomers but can interact strongly with ClpL1, possibly by forming heterooligomers. ClpATPase proteins usually form hexameric rings of homo- or hetero-oligomers (Ogura and Wilkinson, 2001). This could suggest that ClpL2 might require another partner such as ClpL1 form stable oligomers in our BACTH model and by extension in O. oeni. In L. lactis and B. subtilis, ClpE and McsA present CtsR to a proteolytic complex by interacting with CtsR through their zinc finger motifs, which is absent in ClpL1 (Varmanen et al., 2003; Fuhrmann et al., 2009). One explanation for our observations might be that CtsR and ClpL1 in O. oeni interact via another domain than D2-small or a Zinc-finger motif. A possible role of $\mathrm{ClpX}$, which has a zinc-finger pattern at its amino-terminal region, cannot be excluded.

The carboxy-terminal region of CtsR may be involved in physical interaction with the chaperone since three out of the four possible BACTH combinations with a free CtsR C-terminal showed interactions with ClpL1. This is the first study to suggest a role for C-terminal domain of CtsR. Indeed, while the amino-terminal region including the dimerization domain, the
DNA binding-domain and the thermo-sensing domain, is wellcharacterized, the role of the C-terminal region is still unknown. It was suggested by Derré et al. that without the C-terminal region, CtsR is sensitive to protease activity and is unstable in vivo (Derré et al., 2000). In O. oeni, the C-terminal domain of CtsR would be recognized by Clp ATPases to be stabilized, as shown for ClpL in S. mutans (Tao and Biswas, 2013).

We propose the following model as a model of CtsR activity regulation in O. oeni (Figure 5). In agreement with the results of Tao and Biswas showing that ClpL stabilizes CtsR bound to its operator sequence in $S$. mutans, ClpL1 would act similarly under optimal conditions (Figure 5A). Under heat stress conditions, above $33^{\circ} \mathrm{C}$, the CtsR-ClpL1 complex would dissociate from the operator site, allowing stress gene expression (Figure 5B). ClpL1 would address inactive CtsR to a proteolytic complex for degradation, such as ClpL2ClpP by interacting with ClpL2 or $\mathrm{ClpCP}$ by interacting with $\mathrm{ClpC}$. The involvement of ClpCP in CtsR degradation was previously proposed in a CtsR regulation model (Derré et al., 2000; Elsholz et al., 2010).

Taken together, our results confirmed in vivo the central involvement of CtsR in stress response in O. oeni, extending an earlier laboratory study using $B$. subtilis as a heterologous host (Grandvalet et al., 2005). Antisense inactivation of $c t s R$ expression impacted stress survival of $O$. oeni, confirming CtsR as a master coordinator of general stress response. In addition, we showed that CtsR-dependent gene expression fully induced at $33^{\circ} \mathrm{C}$ by $\mathrm{O}$. oeni CstR identifying CtsR as an intrinsic heat sensor. Furthermore, interaction of CtsR with ClpL1 suggests it is a likely player involved in controlling CtsR activity.

\section{AUTHOR CONTRIBUTIONS}

MD, FJ, CG, and TM designed the study. MD, FJ, and CG performed the experiments. MD performed the statistical analysis. MD, CG, and TM drafted the manuscript. FJ and HA contributed to the interpretation 
of the results and writing of the manuscript. All authors contributed to manuscript revision, read, and approved the submitted version.

\section{FUNDING}

This work was supported by research funds from the Conseil Régional de Bourgogne - Franche Comté, the Fonds Européen

\section{REFERENCES}

Assad-García, J., Bonnin-Jusserand, M., Garmyn, D., Guzzo, J., Alexandre, H., and Grandvalet, C. (2008). An improved protocol for electroporation of Oenococcus oeni ATCC BAA-1163 using ethanol as immediate membrane fluidizing agent. Lett. Appl. Microbiol. 47, 333-338. doi: 10.1111/j.1472-765X.2008.02435.x

Bartowsky, E. (2017). Oenococcus oeni and the genomic era. FEMS Microbiol. Rev. 41, 84-94. doi: 10.1093/femsre/fux034

Beltramo, C., Desroche, N., Tourdot-Maréchal, R., Grandvalet, C., and Guzzo, J. (2006). Real-time PCR for characterizing the stress response of Oenococcus oeni in a wine-like medium. Res. Microbiol. 157, 267-274. doi: 10.1016/j.resmic.2005. 07.006

Beltramo, C., Grandvalet, C., Pierre, F., and Guzzo, J. (2004). Evidence for multiple levels of regulation of Oenococcus oeni clpP-clpL locus expression in response to stress. J. Bacteriol. 186, 2200-2205. doi: 10.1128/JB.186.7.2200-2205.2003

Benson, A. K., and Haldenwang, W. G. (1993). The sigma B-dependent promoter of the Bacillus subtilis sigB operon is induced by heat shock. J. Bacteriol. 175, 1929-1935. doi: 10.1128/jb.175.7.1929-1935.1993

Brötz-Oesterhelt, H., Beyer, D., Kroll, H.-P., Endermann, R., Ladel, C., Schroeder, W., et al. (2005). Dysregulation of bacterial proteolytic machinery by a new class of antibiotics. Nat. Med. 11, 1082-1087. doi: 10.1038/nm1306

Cavin, J. F., Prevost, H., Lin, J., Schmitt, P., and Divies, C. (1989). Medium for screening Leuconostoc oenos strains defective in malolactic fermentation. Appl. Environ. Microbiol. 55, 751-753.

Chastanet, A., Fert, J., and Msadek, T. (2003). Comparative genomics reveal novel heat shock regulatory mechanisms in Staphylococcus aureus and other Grampositive bacteria. Mol. Microbiol. 47, 1061-1073. doi: 10.1046/j.1365-2958.2003. 03355.x

Chastanet, A., and Msadek, T. (2003). ClpP of Streptococcus salivarius is a novel member of the dually regulated class of stress response genes in Gram-positive bacteria. J. Bacteriol. 185, 683-687. doi: 10.1128/JB.185.2.683-687.2003

Chastanet, A., Prudhomme, M., Claverys, J. P., and Msadek, T. (2001). Regulation of Streptococcus pneumoniae clp genes and their role in competence development and stress survival. J. Bacteriol. 183, 7295-7307. doi: 10.1128/JB. 183.24.7295-7307.2001

Chu-Ky, S., Tourdot-Maréchal, R., Maréchal, P.-A., and Guzzo, J. (2005). Combined cold, acid, ethanol shocks in Oenococcus oeni: effects on membrane fluidity and cell viability. Biochim. Biophys. Acta Biomembr. 1717, 118-124. doi: 10.1016/j.bbamem.2005.09.015

Coucheney, F., Desroche, N., Bou, M., Tourdot-Maréchal, R., Dulau, L., and Guzzo, J. (2005a). A new approach for selection of Oenococcus oeni strains in order to produce malolactic starters. Int. J. Food Microbiol. 105, 463-470. doi: 10.1016/j.ijfoodmicro.2005.04.023

Coucheney, F., Gal, L., Beney, L., Lherminier, J., Gervais, P., and Guzzo, J. (2005b). A small HSP, Lo18, interacts with the cell membrane and modulates lipid physical state under heat shock conditions in a lactic acid bacterium. Biochim. Biophys. Acta Biomembr. 1720, 92-98. doi: 10.1016/j.bbamem.2005. 11.017

Da Silveira, M. G., and Abee, T. (2009). Activity of ethanol-stressed Oenococcus oeni cells: a flow cytometric approach. J. Appl. Microbiol. 106, 1690-1696. doi: 10.1111/j.1365-2672.2008.04136.x

Da Silveira, M. G., Golovina, E. A., Hoekstra, F. A., Rombouts, F. M., and Abee, T. (2003). Membrane fluidity adjustments in ethanol-stressed Oenococcus oeni cells. Appl. Environ. Microbiol. 69, 5826-5832. doi: 10.1128/AEM.69.10.58265832.2003 de Developpement Régional (FEDER), AgroSup Dijon (Appel d'Offre 2013), and the Ministère de l'Enseignement Supérieur, de la Recherche et de l'innovation (France).

\section{ACKNOWLEDGMENTS}

We would like to thank Pascale Serror and Dominique Garmyn for the helpful discussions regarding this work.

Darsonval, M., Msadek, T., Alexandre, H., and Grandvalet, C. (2016). The antisense RNA approach: a new application for in vivo investigation of the stress response of Oenococcus oeni, a wine-associated lactic acid bacterium. Appl. Environ. Microbiol. 82, 18-26. doi: 10.1128/AEM.02495-15

Dautin, N., Karimova, G., Ullmann, A., and Ladant, D. (2000). Sensitive genetic screen for protease activity based on a cyclic AMP signaling cascade in Escherichia coli. J. Bacteriol. 182, 7060-7066. doi: 10.1128/JB.182.24.7060-7066. 2000

Derré, I., Rapoport, G., and Msadek, T. (1999). CtsR, a novel regulator of stress and heat shock response, controls clp and molecular chaperone gene expression in Gram-positive bacteria. Mol. Microbiol. 31, 117-131. doi: 10.1046/j.1365-2958. 1999.01152.x

Derré, I., Rapoport, G., and Msadek, T. (2000). The CtsR regulator of stress response is active as a dimer and specifically degraded in vivo at 37 degrees C. Mol. Microbiol. 38, 335-347. doi: 10.1046/j.1365-2958.2000.02 124.x

Elsholz, A., Michalik, S., Zühlke, D., Hecker, M., and Gerth, U. (2010). CtsR, the Gram-positive master regulator of protein quality control, feels the heat. EMBO J. 29, 3621-3629. doi: 10.1038/emboj.2010.228

Elsholz, A. K. W., Hempel, K., Michalik, S., Gronau, K., Becher, D., Hecker, M., et al. (2011). Activity control of the ClpC adaptor McsB in Bacillus subtilis. J. Bacteriol. 193, 3887-3893. doi: 10.1128/JB.00079-11

Fiocco, D., Capozzi, V., Collins, M., Gallone, A., Hols, P., Guzzo, J., et al. (2010). Characterization of the CtsR stress response regulon in Lactobacillus plantarum. J. Bacteriol. 192, 896-900. doi: 10.1128/JB.01122-09

Frees, D., Savijoki, K., Varmanen, P., and Ingmer, H. (2007). Clp ATPases and ClpP proteolytic complexes regulate vital biological processes in low GC, Grampositive bacteria. Mol. Microbiol. 63, 1285-1295. doi: 10.1111/j.1365-2958.2007. 05598.x

Fuhrmann, J., Schmidt, A., Spiess, S., Lehner, A., Turgay, K., Mechtler, K., et al. (2009). McsB is a protein arginine kinase that phosphorylates and inhibits the heat-shock regulator CtsR. Science 324, 1323-1327. doi: 10.1126/science. 1170088

Grandvalet, C. (2017). Oenococcus oeni: queen of the cellar, nightmare of geneticists. Microbiology 163, 297-299. doi: 10.1099/mic.0.000456

Grandvalet, C., Assad-García, J. S., Chu-Ky, S., Tollot, M., Guzzo, J., Gresti, J., et al. (2008). Changes in membrane lipid composition in ethanol- and acidadapted Oenococcus oeni cells: characterization of the cfa gene by heterologous complementation. Microbiology 154, 2611-2619. doi: 10.1099/mic.0.2007/ 016238-0

Grandvalet, C., Coucheney, F., Beltramo, C., and Guzzo, J. (2005). CtsR is the master regulator of stress response gene expression in Oenococcus oeni. J. Bacteriol. 187, 5614-5623. doi: 10.1128/JB.187.16.5614-5623.2005

Guzzo, J., Delmas, F., Pierre, F., Jobin, M.-P., Samyn, B., Van Beeumen, J., et al. (1997). A small heat shock protein from Leuconostoc oenos induced by multiple stresses and during stationary growth phase. Lett. Appl. Microbiol. 24, 393-396. doi: 10.1046/j.1472-765X.1997.00042.x

Guzzo, J., Jobin, M.-P., and Diviès, C. (1998). Increase of sulfite tolerance in Oenococcus oeni by means of acidic adaptation. FEMS Microbiol. Lett. 160, 43-47. doi: 10.1111/j.1574-6968.1998.tb12888.x

Hüfner, E., Markieton, T., Chaillou, S., Coq, A.-M. C.-L., Zagorec, M., and Hertel, C. (2007). Identification of Lactobacillus sakei genes induced during meat fermentation and their role in durvival and growth. Appl. Environ. Microbiol. 73, 2522-2531. doi: 10.1128/AEM.023 96-06 
Jobin, M. P., Delmas, F., Garmyn, D., Diviès, C., and Guzzo, J. (1997). Molecular characterization of the gene encoding an 18-kilodalton small heat shock protein associated with the membrane of Leuconostoc oenos. Appl. Environ. Microbiol. 63, 609-614.

Jobin, M.-P., Garmyn, D., Diviès, C., and Guzzo, J. (1999). Expression of the Oenococcus oeni trxA gene is induced by hydrogen peroxide and heat shock. Microbiology 145, 1245-1251. doi: 10.1099/13500872-145-5-1245

Karatzas, K. A. G., and Bennik, M. H. J. (2002). Characterization of a Listeria monocytogenes scott a isolate with high tolerance towards high hydrostatic pressure. Appl. Environ. Microbiol. 68, 3183-3189. doi: 10.1128/AEM.68.7. 3183-3189.2002

Karatzas, K. A. G., Wouters, J. A., Gahan, C. G. M., Hill, C., Abee, T., and Bennik, M. H. J. (2003). The CtsR regulator of Listeria monocytogenes contains a variant glycine repeat region that affects piezotolerance, stress resistance, motility and virulence. Mol. Microbiol. 49, 1227-1238. doi: 10.1046/j.1365-2958.2003.03 636.x

Karimova, G., Dautin, N., and Ladant, D. (2005). Interaction network among Escherichia coli membrane proteins involved in cell division as revealed by bacterial two-hybrid analysis. J. Bacteriol. 187, 2233-2243. doi: 10.1128/JB.187. 7.2233-2243.2005

Karimova, G., Pidoux, J., Ullmann, A., and Ladant, D. (1998). A bacterial twohybrid system based on a reconstituted signal transduction pathway. Proc. Natl. Acad. Sci. U.S.A. 95, 5752-5756. doi: 10.1073/pnas.95.10.5752

Karimova, G., Ullmann, A., and Ladant, D. (2000). A bacterial two-hybrid system that exploits a cAMP signaling cascade in Escherichia coli. Methods Enzymol. 328, 59-73. doi: 10.1016/S0076-6879(00)28390-0

Kirstein, J., Dougan, D. A., Gerth, U., Hecker, M., and Turgay, K. (2007). The tyrosine kinase McsB is a regulated adaptor protein for ClpCP. EMBO J. 26, 2061-2070. doi: 10.1038/sj.emboj.7601655

Kirstein, J., Zühlke, D., Gerth, U., Turgay, K., and Hecker, M. (2005). A tyrosine kinase and its activator control the activity of the CtsR heat shock repressor in Bacillus subtilis. EMBO J. 24, 3435-3445. doi: 10.1038/sj.emboj.7600780

Laemmli, U. K. (1970). Cleavage of structural proteins during the assembly of the head of bacteriophage T4. Nature 227, 680-685. doi: 10.1038/227680a0

Law, J., Buist, G., Haandrikman, A., Kok, J., Venema, G., and Leenhouts, K. (1995). A system to generate chromosomal mutations in Lactococcus lactis which allows fast analysis of targeted genes. J. Bacteriol. 177, 7011-7018. doi: 10.1128/jb.177. 24.7011-7018.1995

Lonvaud-Funel, A. (1999). Lactic Acid Bacteria in the Quality Improvement and Depreciation of Wine in Lactic Acid Bacteria: Genetics, Metabolism and Applications. Dordrecht: Springer, 317-331. doi: 10.1007/978-94-017-202 7-4-16

Maitre, M., Weidmann, S., Dubois-Brissonnet, F., David, V., Covès, J., and Guzzo, J. (2014). Adaptation of the wine bacterium Oenococcus oeni to ethanol stress: role of the small heat shock protein Lo18 in membrane integrity. Appl. Environ. Microbiol. 80, 2973-2980. doi: 10.1128/AEM.04178-13

Margalef-Català, M., Araque, I., Weidmann, S., Guzzo, J., Bordons, A., and Reguant, C. (2016). Protective role of glutathione addition against wine-related stress in Oenococcus oeni. Food Res. Int. 90, 8-15. doi: 10.1016/j.foodres.2016. 10.006

Miller, J. H. (1972). Experiments in Molecular Genetics. NewYork, NY: Cold Spring Harbor Laborator, 352-355.

Msadek, T., Dartois, V., Kunst, F., Herbaud, M.-L., Denizot, F., and Rapoport, G. (1998). ClpP of Bacillus subtilis is required for competence development, motility, degradative enzyme synthesis, growth at high temperature and sporulation. Mol. Microbiol. 27, 899-914. doi: 10.1046/j.1365-2958.1998.00 735.x

Nair, S., Derré, I., Msadek, T., Gaillot, O., and Berche, P. (2000). CtsR controls class III heat shock gene expression in the human pathogen Listeria monocytogenes. Mol. Microbiol. 35, 800-811. doi: 10.1046/j.1365-2958.2000.01752.x
Ogura, T., and Wilkinson, A. J. (2001). AAA+ superfamily ATPases: common structure-diverse function. Genes Cells 6, 575-597. doi: 10.1046/j.1365-2443. 2001.00447.x

Salema, M., Lolkema, J. S., San Romão, M. V., and Lourero Dias, M. C. (1996). The proton motive force generated in Leuconostoc oenos by L-malate fermentation. J. Bacteriol. 178, 3127-3132. doi: 10.1128/jb.178.11.3127-3132.1996

Sambrook, J., Fritsch, E., and Maniatis, T. (1989). Molecular Cloning: A Laboratory Manual, 2nd Edn. New York, NY: Cold Spring Harbod Laboratory.

Schulz, A., and Schumann, W. (1996). hrcA, the first gene of the Bacillus subtilis dnaK operon encodes a negative regulator of class I heat shock genes. J. Bacteriol. 178, 1088-1093. doi: 10.1128/jb.178.4.1088-1093.1996

Schumann, W. (2003). The Bacillus subtilis heat shock stimulon. Cell Stress Chaperones 8, 207-217. doi: 10.1379/1466-12682003008

Spano, G., and Massa, S. (2006). Environmental stress response in wine lactic acid bacteria: beyond Bacillus subtilis. Crit. Rev. Microbiol. 32, 77-86. doi: 10.1080/ 10408410600709800

Taketo, A. (1988). DNA transfection of Escherichia coli by electroporation. Biochim. Biophys. Acta 949, 318-324. doi: 10.1016/0167-4781(88)90158-3

Tao, L., and Biswas, I. (2013). ClpL is required for folding of CtsR in Streptococcus mutans. J. Bacteriol. 195, 576-584. doi: 10.1128/JB.01743-12

Tao, L., Chattoraj, P., and Biswas, I. (2012). CtsR regulation in mcsAB-deficient Gram-positive bacteria. J. Bacteriol. 194, 1361-1368. doi: 10.1128/JB.06746-11

Tourdot-Maréchal, R., Gaboriau, D., Beney, L., and Diviès, C. (2000). Membrane fluidity of stressed cells of Oenococcus oeni. Int. J. Food Microbiol. 55, 269-273. doi: 10.1016/S0168-1605(00)00202-6

van Bokhorst-van de Veen, H., Bongers, R. S., Wels, M., Bron, P. A., and Kleerebezem, M. (2013). Transcriptome signatures of class I and III stress response deregulation in Lactobacillus plantarum reveal pleiotropic adaptation. Microb. Cell Fact. 12:112. doi: 10.1186/1475-2859-12-112

Varmanen, P., Vogensen, F. K., Hammer, K., Palva, A., and Ingmer, H. (2003). ClpE from Lactococcus lactis promotes repression of CtsR-dependent gene expression. J. Bacteriol. 185, 5117-5124. doi: 10.1128/JB.185.17.5117-5124. 2003

Yuan, G., and Wong, S. L. (1995). Isolation and characterization of Bacillus subtilis groE regulatory mutants: evidence for $\operatorname{orf} 39$ in the $d n a K$ operon as a repressor gene in regulating the expression of both groE and dnaK. J. Bacteriol. 177, 6462-6468. doi: 10.1128/jb.177.22.6462-6468.1995

Zotta, T., Asterinou, K., Rossano, R., Ricciardi, A., Varcamonti, M., and Parente, E. (2009). Effect of inactivation of stress response regulators on the growth and survival of Streptococcus thermophilus Sfi39. Int. J. Food Microbiol. 129, 211-220. doi: 10.1016/j.ijfoodmicro.2008.11.024

Zuber, U., and Schumann, W. (1994). CIRCE, a novel heat shock element involved in regulation of heat shock operon dnaK of Bacillus subtilis. J. Bacteriol. 176, 1359-1363. doi: 10.1128/jb.176.5.1359-1363.1994

Zúñiga, M., Gómez-Escoín, C. L., and González-Candelas, F. (2011). Evolutionary history of the OmpR/IIIA family of signal transduction two component systems in Lactobacillaceae and Leuconostocaceae. BMC Evol. Biol. 11:34. doi: 10.1186/ 1471-2148-11-34

Conflict of Interest Statement: The authors declare that the research was conducted in the absence of any commercial or financial relationships that could be construed as a potential conflict of interest.

Copyright (c) 2018 Darsonval, Julliat, Msadek, Alexandre and Grandvalet. This is an open-access article distributed under the terms of the Creative Commons Attribution License (CC BY). The use, distribution or reproduction in other forums is permitted, provided the original author(s) and the copyright owner(s) are credited and that the original publication in this journal is cited, in accordance with accepted academic practice. No use, distribution or reproduction is permitted which does not comply with these terms. 